\title{
Tuning the Pr Valence State to Design High Oxygen Mobility, Redox and Transport Properties in the $\mathrm{CeO}_{2}-\mathrm{ZrO}_{2}-\mathrm{PrO}_{\mathrm{x}}$ Phase Diagram
}

\author{
Vincent Frizon, ${ }^{,+}, \Theta$, Jean-Marc Bassat, ${ }^{+}$, Michael Pollet, ${ }^{+}$, Etienne Durand ${ }^{++}$, Julien Hernandez ${ }^{\$}$, Karine \\ Pajot $^{¥}$, Philippe Vernoux ${ }^{\ominus}$ and Alain Demourgues*,+ \\ ${ }^{++}$: CNRS, Université de Bordeaux, ICMCB, 87 avenue du Dr. Albert Schweitzer, 33608 Pessac, France \\ \$: SOLVAY, RIC, 52 rue de la Haie Coq, 93308 Aubervilliers Cedex, France \\ $¥: 78943$ Vélizy-Villacoublay \\ $\Theta:$ IRCELYON, 2 avenue Albert Einstein, F-69626, Villeurbanne Cedex, France \\ * : Corresponding author
}

\begin{abstract}
The preparation and characterization of pure fluorite-type phases allowed exploring the $\mathrm{CeO}_{2}-\mathrm{ZrO}_{2}-\mathrm{PrO}_{\mathrm{x}}(\mathrm{CZP})$ phase diagram. On the basis of magnetic susceptibility measurements, the $\mathrm{Pr}^{4+} / \mathrm{Pr}^{3+}$ molar ratio of several oxides annealed at $\mathrm{T}=700^{\circ} \mathrm{C}$ under air was determined; the higher the $\mathrm{Zr}$ content, the lower the $\mathrm{Pr}^{4+}$ concentration. Thermogravimetric Analysis (TGA) and Temperature Programmed Reduction (TPR) measurements showed the various Pr and Ce reduction steps. The $\mathrm{Pr}^{4+}$ reduction starts at $\mathrm{T}=250^{\circ} \mathrm{C}$ and is maximum around $\mathrm{T}=400^{\circ} \mathrm{C}$. For the most reducible compositions, which exhibit the lowest $\mathrm{Zr}$ content and the highest Pr rate, the reduction phenomena strongly depend on the $\mathrm{Pr} / \mathrm{Ce}$ molar ratio. As a remarkable result, $\mathrm{Pr}$ and Ce reduction can simultaneously take place at lower temperature $\left(\mathrm{T}>430^{\circ} \mathrm{C}\right)$ than for oxides of the $\mathrm{CeO}_{2^{-}}$ $\mathrm{ZrO}_{2}$ solid solution evidencing that the increase of Pr content also allows enhancing the reducibility of $\mathrm{Ce}^{4+}$ at low temperature. On the basis of a discussion taking into account a probability of oxygen surroundings in disordered fluorite networks, and the released oxygen rate in materials after the first reduction step performed at $\mathrm{T}<500^{\circ} \mathrm{C}$, a mapping of the most probable labile oxygen sites in the CZP phase diagram is proposed. In particular, it is shown that for the oxides containing $10 \% \mathrm{Zr}$ at., the most labile oxygen site should be systematically coordinated with one $\mathrm{Zr}$ atom, one $\mathrm{Ce}$ and two $\mathrm{Pr}$ atoms. In the same series $(10 \%$ $\mathrm{Zr}$ at.), electronic transport properties allowed showing semi-conducting behavior with a strong increase of the total conductivity as the Pr content raises. On the basis of the thermal variation of the Seebeck coefficient, these phenomena are associated to electrons and holes hopping, involving intra-atomic charge transfers which depend on the reduction temperature of $\mathrm{Pr}^{4+}$ ions under air. Finally, the oxygen mobility strongly increases with the Pr content in this series. The oxygen tracer self-diffusion coefficient $\mathrm{D}^{*}$ has been estimated by two independent measurements and the best value is around $10^{-8} \mathrm{~cm}^{2} \cdot \mathrm{s}^{-1}$ at $\mathrm{T}=400^{\circ} \mathrm{C}$ for the $\mathrm{Ce}_{0.45} \mathrm{Zr}_{0.1} \mathrm{Pr}_{0.45} \mathrm{O}_{2-\mathrm{x}}$ composition, which is quite high in this temperature range. These fundamental properties of CZP phases design very promising new materials like automotive exhaust catalysts, gas sensors, electrolytes or oxygen

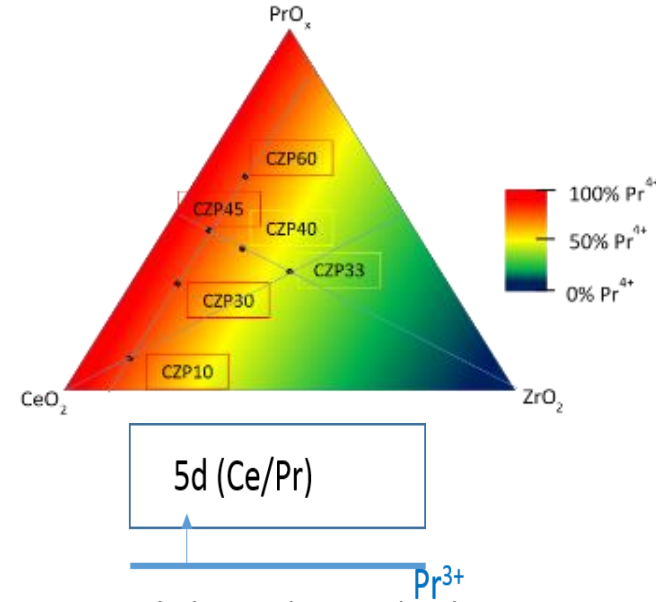

n-type SC behavior (0.38 eV) at low T

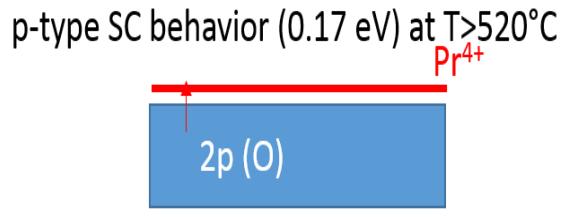
electrodes for solid oxide fuel cells.
\end{abstract}

INTRODUCTION. In the last 20 years, intensive efforts have dealt with the environmental impact decrease of the automotive exhaust gases. Cerium-based oxides, deemed as oxygen buffers, have been widely investigated as key components for Three Way Catalysts (TWCs, stoichiometric air-fuel mixture), Diesel soot abatement (Lean-burn conditions) and wet oxidation ${ }^{1,2,3,4,5}$. Ceria-Zirconia mixed oxides materials have been developed as TWCs ${ }^{1}$. They exhibit high Oxygen Storage Capacity (OSC) with high oxygen release under reducing conditions, fast kinet- ics, high content of reducible $\mathrm{Ce}^{4+}$ at $\mathrm{T}<600^{\circ} \mathrm{C}$, and high thermal stability with rather good surface areas (between 20 and 40 $\mathrm{m}^{2} / \mathrm{g}$ ) stabilized at $\mathrm{T}>1000^{\circ} \mathrm{C}^{6}$. Various crystallographic lattices such as fluorite-type for high $\mathrm{Ce}$ rate, tetragonal distortion of fluorite-type structure for $\mathrm{Zr}$-rich phases and pyrochlore-type structure for equimolar compositions have been characterized for the last 20 years ${ }^{6,7,8}$. The pyrochlore corresponds to a fluorite-type superstructure including both $\mathrm{Ce}^{4+}$ and $\mathrm{Ce}^{3+}$, eightfold coordinated to oxygens, and $\mathrm{Zr}^{4+}$ cations located in a distorted octahedral site as well as oxygen vacancies ordering. The 
corresponding materials have the best redox properties ${ }^{6,7,8,9,10}$. Cations sites distortions as well as cationic ordering play a key role for OSC, Ce reducibility and minimum temperature of reduction.

Praseodymium-based oxides should be able to compete with Cerium-based ones [11]. As compared to Ce, Pr has one electron more in its shell, and $\mathrm{Pr}^{4+}$ appears both less stable and more reducible than $\mathrm{Ce}^{4+}$ (with respect to their respective ionization energies); in addition, the redox potential of $\mathrm{Pr}^{4+} / \mathrm{Pr}^{3+}$ in solution is larger $(2.7 \mathrm{~V} / \mathrm{ENH})$ than that of $\mathrm{Ce}^{4+} / \mathrm{Ce}^{3+}$ (1.7 V/ENH). This elements then easily appears with a mixed valence state combining $\mathrm{Pr}^{4+}$ and $\mathrm{Pr}^{3+}$. For instance its most stable stoichiometric compounds are $\operatorname{Pr}_{7} \mathrm{O}_{12}$ or $\operatorname{Pr}_{24} \mathrm{O}_{44}\left(\mathrm{Pr}_{6} \mathrm{O}_{11}\right)$. The $\operatorname{Pr}_{\mathrm{n}} \mathrm{O}_{2 \mathrm{n}-2 \mathrm{~m}}$ series was extensively studied by Eyring et $a l^{11,12,13}$.

The $\operatorname{Pr}_{1-\mathrm{x}} \mathrm{Zr}_{\mathrm{x}} \mathrm{O}_{2-\mathrm{y}}$ solid solution has already been investigated $^{14}$; the materials exhibit mixed valence states associated to oxygen vacancies with redox processes occurring at low temperature. In these compounds, the higher the $\mathrm{Zr}$ content, the lower the Pr valence state: the larger $\mathrm{Pr}^{3+}-\mathrm{O}^{2-}$ bond is compensated by the smaller $\mathrm{Zr}^{4+}-\mathrm{O}^{2-}$ bond distance while simultaneously oxygen vacancies are formed. The $\mathrm{Zr}^{4+}$ ions stabilization in distorted octahedral site is at the origin of the formation of stoichiometric compositions stabilizing the oxygen vacancies in a fluorite-type structure. In particular, it was evidenced that in the Pr-rich compounds $\stackrel{14}{ }$, high amounts of $\operatorname{Pr}^{4+}$ ions could be reduced under air even at low temperature $\left(\mathrm{T}<250^{\circ} \mathrm{C}\right)$. In addition, the fluorite-type superstructure ( $\mathrm{SG}: I a-3)$ of reduced compositions $\left(\mathrm{T}=900^{\circ} \mathrm{C}\right.$ under $\left.\mathrm{Ar} / 5 \% \mathrm{H}_{2}\right)$ exhibits both a cationic and oxygen vacancies ordering: $\mathrm{Zr}^{4+}$ cations are stabilized in flattened octahedral sites allowing the formation of oxygen vacancies and the stabilization of $\mathrm{Pr}^{3+}$.

Following this work, a $\mathrm{CeO}_{2}$ incorporation in the $\mathrm{Pr}$ rich compounds $\left(\operatorname{Pr}_{1-\mathrm{x}} \mathrm{Zr}_{\mathrm{x}} \mathrm{O}_{2-\mathrm{y}}, \mathrm{x} \leq 0.5\right)$ has been investigated ${ }^{15,16}$. $\mathrm{Zr}$-rich compounds ( $\mathrm{Zr}$ molar content between 0.55 and 0.75 ) exhibit the best thermal stability with high OSC for low Pr rate (between 0.03 and 0.10$){ }^{15,16}$. At lower $\mathrm{Zr}$ content, the $\mathrm{Zr}_{0.1}\left(\mathrm{Ce}_{1-}\right.$ $\left.{ }_{x} \operatorname{Pr}_{x}\right)_{0.9} \mathrm{O}_{2-y}$ solid solution offers an optimal OSC with a bell curve peaking for $\mathrm{x}=0.5$ and the oxygen vacancies rate, associated to $\mathrm{Pr}^{4+} / \mathrm{Pr}^{3+}$ molar ratio, should be responsible for these enhanced $\mathrm{OSCs}^{22}$. Indeed, the OSC is closely related to both the reducibility and the oxygen mobility, which occurs thanks to the oxygen deficiency allowed by the Pr substitution and the formation of the $\mathrm{Pr}^{4+} / \mathrm{Pr}^{3+}$ mixed valence state. For Ce-rich oxides (molar rate $>0.66$ ), the $\mathrm{Zr}$ substitution leads to a decrease in the total (ionic and electronic) conductivity when $\mathrm{p}\left(\mathrm{O}_{2}\right)$ decreases. This is associated with a significant reduction of $\mathrm{Pr}^{4+}$ to $\mathrm{Pr}^{3+}$ in the oxygen impoverished compound with the decrease of the activation energy of the carriers when the compound gains oxygen upon annealing at high temperature ${ }^{17,18}$.

However, no information has been given on Pr valence states in the oxidized or reduced phases. The incorporation of $2 \%$ Pr into the $\mathrm{Ce}_{0.8} \mathrm{Gdd}_{0.2} \mathrm{O}_{1.9}$ network contributes to increase the p-type electronic conductivity by a factor of 3 but no significant changes were observed in the ionic conductivity ${ }^{19}$. Moreover, dealing with $\mathrm{Ce}_{1-\mathrm{x}} \mathrm{Pr}_{\mathrm{x}} \mathrm{O}_{2-\delta}$ solid solution (Ce-rich phases), in-situ optical absorption and electrochemical impedance spectroscopy show the variation of oxygen non-stoichiometry at elevated temperature and at various $\mathrm{p}\left(\mathrm{O}_{2}\right)$, leading to follow the optically absorbing center $\left(\operatorname{Pr}^{4+}\right)$ concentration ${ }^{20}$.
Density Functional Theory (DFT) was used to obtain the equilibrium geometries and energies of ceria-based solid solutions ${ }^{21}$. For instance, as the oxygen vacancies were induced in a site directly coordinated with $\mathrm{Pd}$, a strong reduction in the oxygen vacancy formation energy was observed and explained the observed high activity of $\mathrm{Ce}_{1-\mathrm{x}} \mathrm{Pd}_{\mathrm{x}} \mathrm{O}_{2-\delta}$ complex oxides for redox reactions $^{21}$.

Then, in this series the $\mathrm{Pr}^{4+} / \mathrm{Pr}^{3+}$ molar ratio appears as a key feature. This work deals with the partial exploration of the $\mathrm{CeO}_{2}-\mathrm{ZrO}_{2}-\mathrm{PrO}_{\mathrm{x}}$ phase diagram with a careful control of the $\mathrm{Pr}^{4+}$ content, accurately determined from both magnetic measurements and thermogravimetric analysis performed under $\mathrm{Ar} / 5 \% \mathrm{H}_{2}$. In a second step, the reducibility properties involving $\mathrm{Pr}^{4+}$ and $\mathrm{Ce}^{4+}$ species are discussed. Although the oxygen deficiency is always mentioned as an important parameter in the literature, the identification of labile oxygen and its local environment in its tetrahedral site is hardly ever discussed despite its crucial role for the Oxygen Storage Capacity and mobility properties. Herein, we propose a mapping of the most labile oxygen environment in the $\mathrm{CeO}_{2}-\mathrm{ZrO}_{2}-\mathrm{PrO}_{\mathrm{x}}$ outlined phase diagram, using a multinomial law which helps analyzing the oxygen mobility in association with the redox properties.

The temperature dependence of the total conductivity and the Seebeck coefficient has been measured and a schematic band diagram is proposed. The control of $\mathrm{Pr}^{4+} / \mathrm{Pr}^{3+}$ mixed valences in connection with each composition is shown to allow tuning the transport properties (nature and mobility of the charge carriers).

Finally, the chemical oxygen diffusion coefficients $\mathrm{D}_{\text {Chem }}$ were determined for the most conductive sample using electronic conductivity relaxation experiments analyzed with a Crank model and isotopic exchange experiments monitored by SIMS analysis.

\section{EXPERIMENTAL SECTION}

Several oxides have been prepared starting from nitrates precursors (SOLVAY), co-precipitated in basic medium $(\mathrm{pH}=10)$. At $\mathrm{pH}=10$, all Ce-Zr-Pr hydroxydes and oxyhydroxides precipitate. Precipitates were washed six times with ammonia $(\mathrm{M} / 100)$ and twice with ethanol followed by a slow drying at $\mathrm{T}=50^{\circ} \mathrm{C}$ under air. All these oxides were annealed in air at $\mathrm{T}=700^{\circ} \mathrm{C}$ and then at $\mathrm{T}=1400^{\circ} \mathrm{C}$ during 12 hours; they crystallize with the fluorite-type structure and no phase transition is observed. All compositions and nomenclature are given in Table1; the samples are named after their cationic composition (e.g. $\mathrm{CZ}$ contains only $\mathrm{Ce}$ and $\mathrm{Zr}$ and $\mathrm{CZP}$ contains $\mathrm{Pr}$ in addition) and their Pr content (e.g. CZP60 contains 60 molar\% of $\mathrm{Pr}$ and 40 molar\% of $\mathrm{Ce}$ and $\mathrm{Zr}$ ).

Cation molar ratios were checked with the inductively coupled plasma atomic emission spectroscopy (ICP-AES) technique and correspond to the targeted chemical composition. The samples were first dissolved using hydrochloric acid and heated at $200^{\circ} \mathrm{C}$ for $15 \mathrm{~min}$ using a microwave digestion system (CEM, MARS).

Powder X-Ray diffraction patterns have been collected on a Phillips X'Pert MPD X-ray diffractometer with Bragg-Brentano geometry using $\mathrm{K} \alpha 1 / \mathrm{K} \alpha 2$ radiations $\left(8^{\circ}<2 \theta<80^{\circ}\right.$ step of $0.017^{\circ}$ and counting time of $\left.60 \mathrm{~s}\right)$. Diffractograms have been refined using the Rietveld method and Fullprof package with conventional reliability factors. The unit cell 
and profile parameters leading to determine the average crystallite size have been refined. All the diffraction patterns have been indexed on the basis of Fluorite-type structures (SG : Fm-3m).

Surface areas were determined using Brunauer-Emmet-Teller (BET) calculations performed on $\mathrm{N}_{2}$ adsorption isotherms at $\mathrm{T}=-196^{\circ} \mathrm{C}$, recorded with a Tristar Surface Area and Porosity apparatus from Micromeritics. Outgassing temperature was set at $300^{\circ} \mathrm{C}$ for all the samples.

Samples for transmission electron microscopy (TEM) were prepared by suspending the powder in alcohol by ultrasonication and depositing a drop of the suspension on a copper grid covered with a carbon film. The grid was finally airdried for 15 min. TEM, high resolution TEM (HRTEM) and scanning TEM coupled with energy dispersive X-Ray spectroscopy (STEM-EDX) observations were performed using a JEOL 2200 FS equipped with a field emission gun, operating at $200 \mathrm{kV}$ and with a point resolution of $0.23 \mathrm{~nm}$. Highresolution transmission electron microscopy micrographs were acquired with a Gatan Ultrascan CCD $2 \mathrm{k}-2 \mathrm{k}$, while digital diffractograms were calculated using the Gatan Digital Micrograph program. Moreover, in order to be representative and statistically meaningful, numerous images from several regions of various samples were recorded and the most characteristic results are presented here.

The thermogravimetric analysis (TGA) have been carried out on SETARAM Setsys evolution under $\mathrm{Ar} / 5 \% \mathrm{H}_{2}$ flux $(50$ $\mathrm{ml} / \mathrm{min}$ ) with a speed rate of $5^{\circ} \mathrm{C} / \mathrm{min}$ up to $\mathrm{T}=900^{\circ} \mathrm{C}$. TGA experiments have been also carried out under air or $\mathrm{Ar}$ up to $\mathrm{T}=800^{\circ} \mathrm{C}$ (speed rate: $5^{\circ} \mathrm{C}$ min for air atmosphere and $3^{\circ} \mathrm{C} / \mathrm{min}$ for $\mathrm{Ar}$ atmosphere) for oxides with high $\mathrm{Pr}$ content. Samples were pre-treated at $\mathrm{T}=400^{\circ} \mathrm{C}$ for 1 hour under $\mathrm{O}_{2}$ flow $(100 \mathrm{ml} / \mathrm{min})$ to avoid the partial reduction of the compounds. The same TGA experiments carried out after pre-treatment at $\mathrm{T}=700^{\circ} \mathrm{C}$ under air (to remove water/carbonates) into the TGA apparatus, do not influence the temperature and reduction rates in CZP samples. Temperature Programmed Reduction (TPR) have been performed on Micromeritics AutoChemII $2950 \mathrm{HP}$ under $\mathrm{Ar} / 1 \% \mathrm{H}_{2}\left(100 \mathrm{ml} / \mathrm{min}\right.$ ) up to $800^{\circ} \mathrm{C}$ (speed rate: $10^{\circ} \mathrm{C} / \mathrm{min}$ ) with a mass spectrometer Inficon JPC400 to detect $\mathrm{H}_{2}$ consumption and $\mathrm{H}_{2} \mathrm{O}$ formation. The thermal expansion behavior has been investigated by dilatometry from room temperature to $1400^{\circ} \mathrm{C}$ under air (speed rate: $5^{\circ} \mathrm{C} / \mathrm{min}$ ) on NETZSCH DIL 402C dilatometer.

The Curie constants and $\theta p$ Weiss temperatures values have been deduced from magnetic susceptibilities measurements $(1 / \chi=(\mathrm{T}+\theta \mathrm{p}) / \mathrm{C}, \chi=\mathrm{M} . \mathrm{H})$, the magnetizations being recorded between $125 \mathrm{~K}$ and $300 \mathrm{~K}$ (speed rate: $10 \% \mathrm{~min}$ ) with a magnetic field of 18000 Oe. Magnetic measurements have been performed on a MicroSense EZ7 vibrating magnetometer. As the Curie constant is proportional to the concentration of the paramagnetic species, the $\operatorname{Pr}^{3+}\left(4 \mathrm{f}^{2}\right)$ and $\operatorname{Pr}^{4+}\left(4 \mathrm{f}^{1}\right)$ contents in the various compounds can be deduced from magnetic data.

The sintering of uniaxially pressed powders obtained after slow drying at $50^{\circ} \mathrm{C}$ (see preparation section) allow obtaining dense pellets with a compactness higher than $90 \%$. The temperature variation of the total conductivity has been measured by the four-point probe method which has been carried out from room temperature to $1000 \mathrm{~K}$ under air using Pt as contact materials. The total conductivity have been deduced from the $\mathrm{R}$ resistance $(1 / \sigma=R . s / 1$ where $s$ and 1 are respectively the cross section area and the length of the pellet) by applying electric currents which vary between $0.5 \mu \mathrm{A}$ and $3 \mathrm{~mA}$. By measuring the voltage difference $\Delta \mathrm{V}$ between the hot and cold sides of the material versus temperature and the $\Delta \mathrm{T}$ change in temperature between the two sides, the thermal variation of the Seebeck coefficient $\alpha=\Delta \mathrm{V} / \Delta \mathrm{T}$ was evaluated.

The oxygen diffusion $\left(D^{*}\right)$ coefficient was determined using dense pellets by the Isotopic Exchange Depth Profile (IEDP) technique combining isotopic exchange of ${ }^{18} \mathrm{O}$ (used as an oxygen tracer) for ${ }^{16} \mathrm{O}$ then Secondary Ion Mass Spectrometry (SIMS) analyses. The complete procedure is detailed in refs $^{23,24}$. Prior to each exchange, a pre-annealing step was performed, which consisted in equilibrating the sample at the temperature of interest (same temperature as the subsequent exchange) in natural ${ }^{16} \mathrm{O}$ oxygen $(99.9 \%$ purity) at 210 mbar. The time used for the pre-anneal step in natural oxygen was always much longer (at least five times) than the exchange time. Then the sample was exchanged in an ${ }^{18} \mathrm{O}$ enriched gas $(97 \%$, Eurisotop) at the same temperature and oxygen partial pressure, for a controlled duration. In order to limit the oxygen stoichiometry change during the heating and cooling ramps, a tubular furnace was rapidly rolled on to set the sample to the annealing temperature and later rolled off to rapidly cool it down. The ${ }^{18} \mathrm{O}$ penetration profiles, i.e normalized ${ }^{18} \mathrm{O}$ isotopic fraction $\left({ }^{18} \mathrm{O} /\right.$ $\left.\left({ }^{16} \mathrm{O}+{ }^{18} \mathrm{O}\right)\right)$, were recorded as a function of the analyzed depth using a Cameca ${ }^{\circledR}$ IMS 6F SIMS apparatus with a $\mathrm{Cs}^{+}$ions source. The oxygen profiles were then fitted using an appropriate solution to the diffusion equation given by Crank, for a solution of the second Fick's law of gas diffusion in solids ${ }^{25}$.Electrical conductivity relaxation (ECR) measurements were carried out using the four probe method. The $\mathrm{pO}_{2}$ surrounding the sample was alternatively switched between 0.21 (air) and about $5 \times 10^{-5}$ (Ar) bars. Based on the Crank model ${ }^{25}$, the ratio $\frac{M_{t}}{M_{\infty}}=\frac{\sigma_{t}-\sigma_{0}}{\sigma_{\infty}-\sigma_{0}}, \sigma_{t}, \sigma_{0}$ and $\sigma_{\infty}$ being the conductivity values at $\mathrm{t}, \mathrm{t}=0$ and $\mathrm{t}=\infty$, respectively, was fitted, which allowed to model $k_{\text {Chem }}$ and $D_{\text {Chem, }}$, the chemical surface exchange and diffusion coefficients, respectively.

\section{RESULTS AND DISCUSSION}

\section{1-Unit cell parameter, crystallite size, surface area and ho- mogeneity}

Raw Diffractograms are plotted in Figure 1 (following annealing at $700^{\circ} \mathrm{C}$ ) and Figure S1 (following annealing at $1400^{\circ} \mathrm{C}$ ). $\mathrm{XRD}$ analysis on the samples annealed at $700^{\circ} \mathrm{C}$ in air allows identifying single phases corresponding to the cubic-fluorite type structure (SG: Fm-3m). In these structures, the small ionic radius of $\mathrm{Zr}^{4+}$ is partly compensated by the presence of larger ions such as $\operatorname{Pr}^{3+}\left(r\left(\operatorname{Pr}^{3+}\right)=1.12 \AA\right.$ in eight-fold oxygen-coordinated environment ). Nevertheless, the unit-cell parameters, characterizing the powders annealed at $700^{\circ} \mathrm{C}$ under air, systematically decrease with the zirconium content increase: a $(\mathrm{CZP} 10)=5.404 \AA>\mathrm{a}(\mathrm{CZP} 40)=5.394 \AA>\mathrm{a}(\mathrm{CZP} 33)=$ 5.366 $\AA$ (Table 1). The comparable ionic sizes of $\mathrm{Ce}^{4+}$ and $\operatorname{Pr}^{4+}$ (respectively equal to $0.99 \AA$ and $0.97 \AA$ when eight-fold coordinated to oxygen), as well as the occurrence of $\operatorname{Pr}^{3+}$ ions may explain the very small differences observed between the unit 
cell parameters. In particular, the CZP33 unit-cell parameter (33 molar\% $\mathrm{Zr}$ ) is expected to be significantly lower than that of $\mathrm{CZ}$ (20 molar\% Zr) but both are almost equal. It can therefore be anticipated that CZP33 oxide contains a non-negligible amount of larger $\mathrm{Pr}^{3+}$ ions. The same remark holds between $\mathrm{CZ}$ and CZP40 oxides where a larger amount of $\mathrm{Pr}^{3+}$ is also expected in the latter case (Table 1).

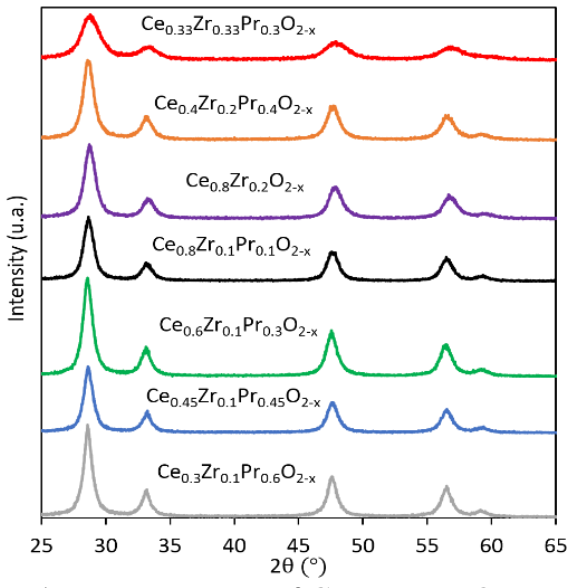

Fig. 1 : Powder XRD patterns of $\mathrm{Ce}_{1-x-y} \mathrm{Zr}_{\mathrm{x}} \mathrm{Pr}_{\mathrm{y}} \mathrm{O}_{2-\mathrm{z}}$ complex oxides annealed at $700^{\circ} \mathrm{C}$ under air.

\begin{tabular}{|c|c|c|c|c|c|c|c|}
\hline Composition & Name & $\begin{array}{c}\text { Lattice } \\
\text { parameter } \\
(\bar{A})\end{array}$ & $\begin{array}{c}\text { Lattice } \\
\text { parameter at } \\
1400^{\circ} \mathrm{C}(\overline{\mathrm{A}})\end{array}$ & $\begin{array}{l}\text { Cristallites } \\
\text { size }(\mathrm{nm})\end{array}$ & $\begin{array}{c}\text { Surface } \\
\text { area } \\
\left(\mathrm{m}^{2} / \mathrm{g}\right)\end{array}$ & $\begin{array}{l}\text { Pore } \\
\text { size } \\
(\mathrm{nm})\end{array}$ & $\begin{array}{c}\text { Pore } \\
\text { volume } \\
\left(\mathrm{cm}^{3} / \mathrm{g}\right)\end{array}$ \\
\hline $\mathrm{Ce}_{0.33} \mathrm{Zr}_{0.33} \mathrm{Pr}_{0.33} \mathrm{O}_{2-x}$ & CZP33 & $5.366(3)$ & $5.3593(3)$ & $5(1)$ & $65(1)$ & $4-5$ & 0.20 \\
\hline $\mathrm{Ce}_{0.80} \mathrm{Zr}_{0.20} \mathrm{O}_{2 \cdot \mathrm{x}}$ & $\mathrm{Cz}$ & $5.372(2)$ & $5.3539(2)$ & $11(1)$ & $84(1)$ & 6-7 & 0.25 \\
\hline $\mathrm{Ce}_{0.40} \mathrm{Zr}_{0.22} \mathrm{Pr}_{0.40} \mathrm{O}_{2 \cdot \boldsymbol{x}}$ & CZP4O & $5.394(2)$ & $5.3916(2)$ & $8(1)$ & $34(1)$ & - & - \\
\hline $\mathrm{Ce}_{0.8} \mathrm{Zr}_{0.1} \mathrm{Pr}_{0.1} \mathrm{O}_{2-\mathrm{x}}$ & CZP10 & $5.404(1)$ & $5.3941(1)$ & $9(1)$ & $84(1)$ & $5-6$ & 0.26 \\
\hline $\mathrm{Ce}_{0.6} \mathrm{Zr}_{0.1} \mathrm{Pr}_{0.3} \mathrm{O}_{2-\mathrm{x}}$ & CZP3O & $5.406(2)$ & $5.3998(1)$ & $9(1)$ & $52(1)$ & 10 & 0.21 \\
\hline $\mathrm{Ce}_{0.45} \mathrm{Zr}_{0.1} \mathrm{Pr}_{0.45} \mathrm{O}_{2-\mathrm{x}}$ & CZP45 & $5.404(1)$ & $5.4069(2)$ & $9(1)$ & $47(1)$ & $4-6$ & 0.26 \\
\hline $\mathrm{Ce}_{0.3} \mathrm{Zr}_{0.1} \mathrm{Pr}_{0.6} \mathrm{O}_{2-\mathrm{x}}$ & CZP60 & $5.402(2)$ & $5.4274(3)$ & $8(1)$ & $41(1)$ & - & - \\
\hline
\end{tabular}

Table 1 : Structural and textural characteristics of $\mathrm{Ce}_{1-\mathrm{x}-\mathrm{y}} \mathrm{Zr}_{\mathrm{x}-}$ $\mathrm{Pr}_{\mathrm{y}} \mathrm{O}_{2-\mathrm{z}}$ oxides annealed at $700^{\circ} \mathrm{C}$ under air.

After annealing at $1400^{\circ} \mathrm{C}$, the cell parameter decreases in the Pr-free sample (CZ) and increases in the two most Pr-rich samples (CZP45-60) while it remains almost constant in the other samples. For Pr-free sample, we assume that the significant decrease in the cell parameter (from 5.372(2) $\AA$ to 5.3539(2) $\AA$, table 1) should be related to diffusion and cationic reorganization phenomena occurring at high temperature. On the other side, for the Pr-rich samples, the increase in the cell parameter can be associated with a significant increase in the $\operatorname{Pr}^{3+}$ concentration after annealing at very high temperatures (reducing conditions). For all other composition a compromise between these two extrema may occur. Note that the reduction from $\mathrm{Pr}^{4+}$ to $\mathrm{Pr}^{3+}$ is also directly visible on the dilatometry curves (Figure $\mathrm{S} 2$ ) recorded on $\mathrm{CZP} 33$ and $\mathrm{CZP} 45$ pellets under air with a noticeable shrinkage of the pellets, the one on CZP45 being larger, as expected from the higher Pr content.

It is also important to underline that our synthesis protocol allows producing oxides with crystallites size less than or equal to $10 \mathrm{~nm}$. Zr-rich CZP33, whose diffractogram exhibits the largest HWHM (Figure 1), contains the smallest crystallites $(5 \mathrm{~nm})$ in agreement with the results of the literature ${ }^{3,4,5}$. Moreover, it is worth noting that the increase in the Pr rate contributes to a significant reduction of the surface area. On should have to mention that the chemical composition determined by X-ray Photoemission Spectroscopy (XPS, surface information, not presented here) is in very good agreement with the ICP-OES analysis (bulk information, see experimental section)

Since the synthesized materials are monophasic with acceptable surfaces areas and are made up of small crystallites, it is also relevant to check their cationic homogeneity. For this purpose, STEM-EDX measurements were carried out, with the aim to map the different chemical elements over a pre-defined zone, each element being represented by a specific color in Figure.2. The cartographies of $\mathrm{Ce}, \mathrm{Zr}$ and $\mathrm{Pr}$ elements related to the CZP10 and CZP45 compounds are given in Figure S3 (CZP10) and Figure 3 (CZP45), both evidencing a rather good cationic homogeneity.

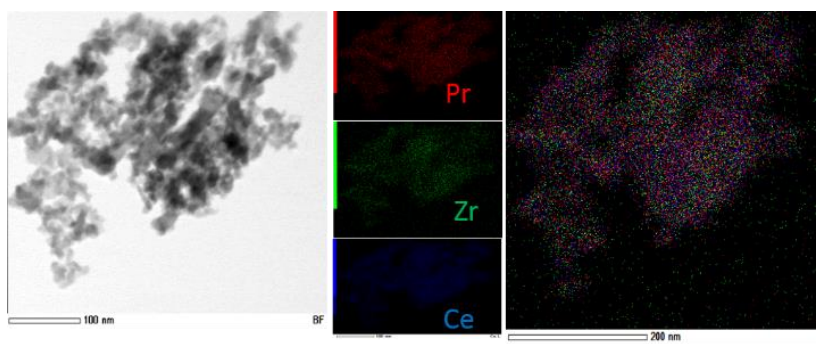

Fig. 2: STEM light field image (left) analysis and EDX elementary analyses of CZP45 complex oxide (right, "three colors" images obtained by addition of the three elementary cartographies).

\section{$2-\operatorname{Pr}^{4+} / \operatorname{Pr}^{3+}$ molar ratio determined by magnetic measure- ments in $\mathrm{Ce}_{1-\mathrm{x}-\mathrm{y}} \mathrm{Zr}_{\mathrm{x}} \mathrm{Pr}_{\mathrm{y}} \mathrm{O}_{2-\mathrm{z}}$ oxides}

Only considering the Curie constant, it is impossible to differentiate between $\mathrm{Ce}^{3+}$ and $\mathrm{Pr}^{4+}$ ions in an oxide with formula $\mathrm{Ce}_{1-\mathrm{x}-\mathrm{y}} \mathrm{Zr}_{\mathrm{x}} \mathrm{Pr}_{\mathrm{y}} \mathrm{O}_{2-\mathrm{z}}$, both having a $4 \mathrm{f}^{1}$ electronic configuration $\left(\mu_{\mathrm{eff}}=2.54 \mu_{\mathrm{B}}, \mathrm{C}=0.806 \mathrm{uem} . \mathrm{K} / \mathrm{mole}\right)$. However, as confirmed by thermodynamic considerations ${ }^{22}$ and Ellingham diagrams, the $\mathrm{Ce}^{4+}$ is stabilized under air atmosphere in fluoritetype structure up to $1600^{\circ} \mathrm{C}$. Furthermore, magnetic measurements of $\mathrm{Ce}_{1-\mathrm{x}} \mathrm{Zr}_{\mathrm{x}} \mathrm{O}_{2}$ solid solutions annealed under air at high temperatures show diamagnetic signals and consequently the absence of $\mathrm{Ce}^{3+}$. Therefore, within our experimental measurements conditions $(\mathrm{T}<400 \mathrm{~K})$, we can assume the only presence of a $\mathrm{Pr}^{4+} / \mathrm{Pr}^{3+}$ mixture and $100 \% \mathrm{Ce}^{4+}$ so that all Curie constants can be calculated per mole of praseodymium only $26,27,28,29,30,31,32$.

Magnetic measurements were performed on the different materials annealed at $\mathrm{T}=700^{\circ} \mathrm{C}$ and the linear variation of the reciprocal magnetic susceptibility was plotted versus temperature (see e.g. CZP45 in Figure S4) to extract the Curie constants (Table 2). Taking into account the theoretical effective moments of $\operatorname{Pr}^{4+}$ and $\operatorname{Pr}^{3+}$ ions $\left(2.54 \mu_{\mathrm{B}}\right.$ and $3.58 \mu_{\mathrm{B}}$, respectively, $\left.\mathrm{C}_{\mathrm{Pr} 4+}=0.806 \mathrm{uem} . \mathrm{K} / \mathrm{mole}, \mathrm{C}_{\mathrm{Pr} 3+}=1.602 \mathrm{uem} . \mathrm{K} / \mathrm{mole}\right)$, their proportion can be evaluated for all the $\mathrm{Ce}_{1-\mathrm{x}-\mathrm{y}} \mathrm{Zr}_{\mathrm{x}} \mathrm{Pr}_{\mathrm{y}} \mathrm{O}_{2-\mathrm{z}}$ series (Table 2 and Figure 3). At low temperature (T<175K), a slight deviation to the Curie-Weiss law must be mentioned leading to consider the more general Van-Vleck formula taking into account the various population of fundamental and excited states and the spin-orbit coupling effect ${ }^{26-32}$. 
Table 2: Curie constants values, $\mathrm{Pr}^{4+} / \mathrm{Pr}^{3+}$ molar ratios and Weiss temperature of $\mathrm{Ce}_{1-\mathrm{x}-\mathrm{y}} \mathrm{Zr}_{\mathrm{x}} \mathrm{Pr}_{\mathrm{y}} \mathrm{O}_{2-\mathrm{z}}$ oxides annealed at $700^{\circ} \mathrm{C}$ under air, deduced from Curie-Weiss law $1 / \chi=(\mathrm{T}-\theta \mathrm{p}) / \mathrm{C}$.

\begin{tabular}{cccc}
\hline Compositions & $\mathrm{Ce}_{0.33} \mathrm{Zr}_{0.33} \mathrm{Pr}_{0.33} \mathrm{O}_{2-x}$ & $\mathrm{Ce}_{0.40} \mathrm{Zr}_{0.20} \mathrm{Pr}_{0.40} \mathrm{O}_{2-x}$ & $\mathrm{Ce}_{0.8} \mathrm{Zr}_{0.1} \mathrm{Pr}_{0.1} \mathrm{O}_{2-x}$ \\
\hline Curie constant & 1.250 & 1.200 & 1.099 \\
(uem CGS. $\left.\mathrm{K}^{-1}\right)$ & & 81 & 46 \\
$\Theta_{p}(\mathrm{~K})$ & 47 & $51(1)$ & $66(1)$ \\
$\mathrm{Pr}^{4+}(\%)$ & $44(1)$ & $49(1)$ & $34(1)$ \\
$\mathrm{Pr}^{3+}(\%)$ & $56(1)$ & 0.959 & 1.067 \\
\hline Compositions & $\mathrm{Ce}_{0.6} \mathrm{Zr}_{0.1} \mathrm{Pr}_{0.3} \mathrm{O}_{2-x}$ & $\mathrm{Ce}_{0.45} \mathrm{Zr}_{0.1} \mathrm{Pr}_{0.45} \mathrm{O}_{2-x}$ & $\mathrm{Ce}_{0.3} \mathrm{Zr}_{0.1} \mathrm{Pr}_{0.6} \mathrm{O}_{2-x}$ \\
\hline Curie constant & 1.078 & 40 & 98 \\
(uem CGS. $\left.\mathrm{K}^{-1}\right)$ & & 81 & $67(1)$ \\
$\Theta_{p}(\mathrm{~K})$ & 61 & $81(1)$ & $33(1)$ \\
$\mathrm{Pr}^{4+}(\%)$ & $66(1)$ & $19(1)$ & \\
$\mathrm{Pr}^{3+}(\%)$ & $34(1)$ & &
\end{tabular}
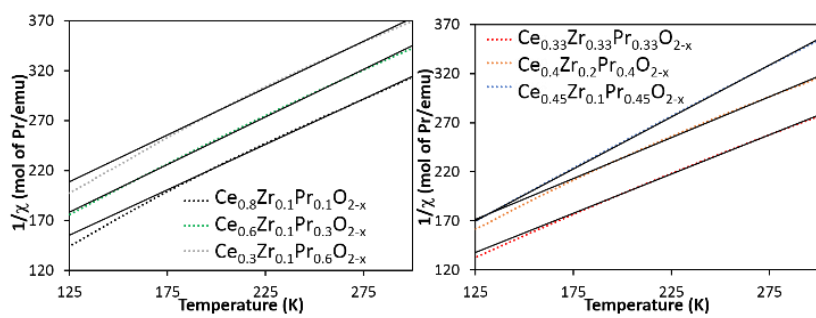

Fig. 3: Temperature dependence of the magnetic susceptibility inverse for the $\mathrm{Ce}_{1-\mathrm{x}-\mathrm{y}} \mathrm{Zr}_{\mathrm{x}} \mathrm{Pr}_{\mathrm{y}} \mathrm{O}_{2-\mathrm{z}}$ oxides (with constant $\mathrm{Zr}=0.1$ content, left, and variable $\mathrm{Zr}$ rate with constant $\mathrm{Ce} / \mathrm{Pr}$ molar ratio, right) annealed at $700^{\circ} \mathrm{C}$ under air.

Data gathered in Table 2 and plotted in Figure 4 clearly evidence that the lower the $\mathrm{Zr}$ rate, the higher the $\mathrm{Pr}^{4+}$ content in this series, the only exception being for CZP45 for which the $\mathrm{Pr}^{4+}$ proportion peaks at $81 \%$ while it is at ca $66 \%$ in all other compounds with $\mathrm{Zr}$ at 10 molar\%. Others CZP compositions (not mentioned in the text) have been prepared and characterized by XRD and magnetic measurements in order to have the best representation of this phase diagram (Figure. 4). Only some representative compounds of the CZP series have been presented and discussed in this manuscript. These results can be globally analyzed in terms of competitive bonds around $\mathrm{Zr}^{4+}$ and $\mathrm{O}^{2-}$ ions. $\mathrm{Zr}^{4+}$ ion is more polarizing than $\mathrm{Ce}^{4+} / \mathrm{Pr}^{4+} / \mathrm{Pr}^{3+}$, because of its lower ionic radius and its higher charge. On the basis of magnetic measurement performed under air at low temperatures, the higher the $\mathrm{Zr}^{4+}$ content, the higher the $\mathrm{Pr}^{3+}$ rate (the blue color zone on Figure 4), leading to the creation of oxygen vacancies in fluorite-type network. Thus, the larger $\mathrm{Pr}^{3+}$ $0^{2-}$ bond length (more ionic) compensates for the smaller $\mathrm{Zr}^{4+}$ $\mathrm{O}^{2-}$ bond distance (more covalent). . The somewhat higher oxidation degree in CZP45 arises from the composition, with equal $\mathrm{Ce}$ and $\mathrm{Pr}$ concentration, and will be discussed later. The spin interactions as given by the Weiss temperatures are all anti-ferromagnetic but no clear trend emerges from our results.

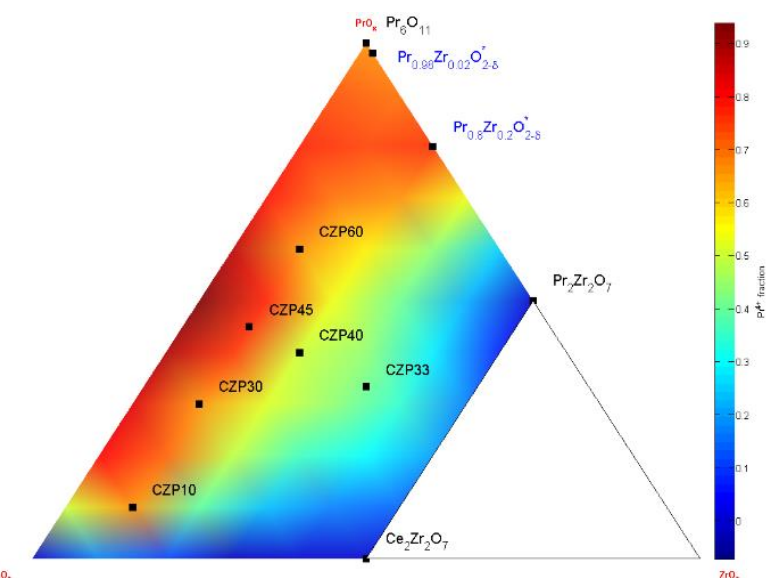

Fig. 4: $\mathrm{CeO}_{2}-\mathrm{ZrO}_{2}-\mathrm{PrO}_{\mathrm{x}}$ ternary phase diagram including the studied $\mathrm{Ce}_{1-\mathrm{x}-\mathrm{y}} \mathrm{Zr}_{\mathrm{x}} \mathrm{Pr}_{\mathrm{y}} \mathrm{O}_{2-\mathrm{z}}$ compositions (CZP). The $\mathrm{Pr}^{4+}$-rich and $\mathrm{Pr}^{3+}$-rich zones are roughly shown. The $\mathrm{Pr}^{4+} / \mathrm{Pr}^{3+}$ molar ratio has been determined on the basis of magnetic measurements performed on each CZP oxide after annealing at $\mathrm{T}=700^{\circ} \mathrm{C}$ under air.

\section{3- $\mathrm{Pr}^{4+} / \mathrm{Ce}^{4+}$ reduction steps determined by thermogravi- metric analysis and temperature programmed reduction}

Taking into account the $\mathrm{Pr}^{4+} / \mathrm{Pr}^{3+}$ molar ratio values previously determined by magnetic measurements, thermogravimetric analysis were performed under $\mathrm{Ar} / 5 \% \mathrm{H}_{2}$ flow in order to estimate the oxygen release related to the $\mathrm{Pr}^{4+} / \mathrm{Ce}^{4+}$ reduction process. Figure 5 plots the corresponding TGA curves and their derivatives dTG (top graph for compounds containing 20 or $33 \%$ at. $\mathrm{Zr}$ and the bottom graph for those containing $10 \%$ at. $\mathrm{Zr})$. The weight loss at low temperatures $\left(<300^{\circ} \mathrm{C}\right)$ is due to the departure of water molecules and carbonates adsorbed on the powders surface. The materials reduction takes place beyond this temperature, the reduction phenomena occurring by successive waves. By considering the minimum of dTG derivatives, various reduction steps can be identified and quantified. Depending on the composition, one to three main reduction steps can be more or less easily evidenced. The weight losses, change in stoichiometry and evolution of $\mathrm{RE}^{4+} / \mathrm{RE}^{3+}$ rare earth molar ratios data, are reported in Table $\mathrm{S} 1$. For each compound, these data are given during the three reduction steps: $300^{\circ} \mathrm{C}<\mathrm{T}$ $<500^{\circ} \mathrm{C}$, then up to $700^{\circ} \mathrm{C}$ and finally up to $900^{\circ} \mathrm{C}$. The same starting hypothesis was used than for the magnetic titration: cerium is solely considered as $\mathrm{Ce}^{4+}$ in the pristine materials before reduction. Then the stoichiometry of $\mathrm{CZP} 33$ before TGA experiment is $\mathrm{Ce}_{0.33} \mathrm{Zr}_{0.33} \operatorname{Pr}_{0.33} \mathrm{O}_{1.9}$ and becomes $\mathrm{Ce}_{0.33} \mathrm{Zr}_{0.33} \operatorname{Pr}_{0.33} \mathrm{O}_{1.84}$ after reduction at $470^{\circ} \mathrm{C}$. At this temperature, $10 \%$ of the Prions remain at the oxidation state +4 . At $700{ }^{\circ} \mathrm{C}$, all the $\mathrm{Pr}$ ions are in the trivalent state and the reduction of $\mathrm{Ce}^{4+}$ to $\mathrm{Ce}^{3+}$ begins. At $900{ }^{\circ} \mathrm{C}, 63 \%$ of the cerium are in the trivalent state, and the composition of CZP33 oxide is finally $\mathrm{Ce}_{0.33} \mathrm{Zr}_{0.33} \operatorname{Pr}_{0.33} \mathrm{O}_{1.72}$. Considering CZP40, CZP10 and CZP30, all $\mathrm{Pr}^{4+}$ ions are reduced during the first reduction step at low temperatures. 


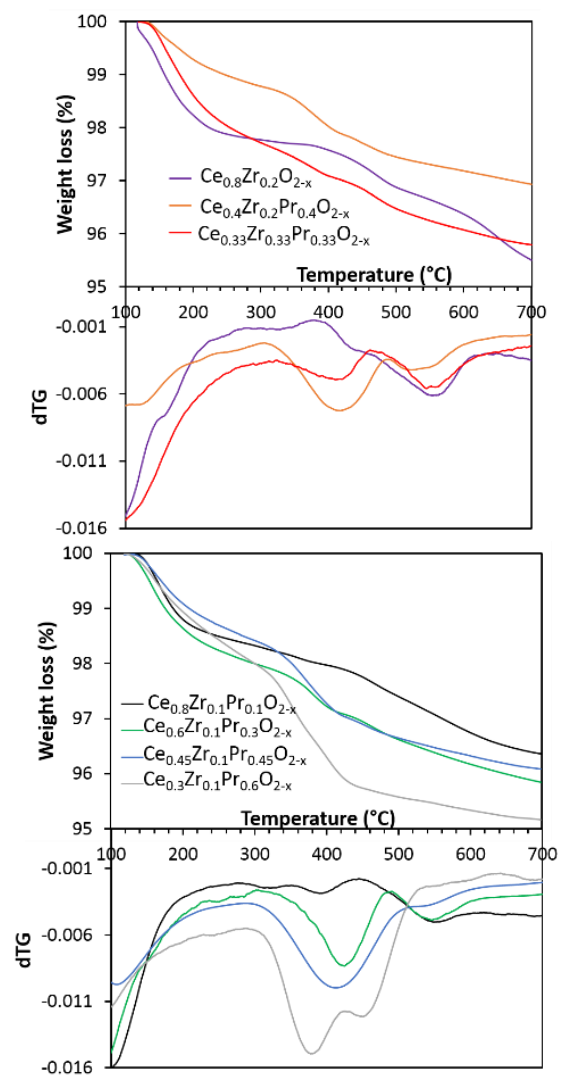

Fig. 5 : Thermogravimetric curve (TG) and first derivative curve (dTG) obtained for the $\mathrm{Ce}_{1-\mathrm{x}-\mathrm{y}} \mathrm{Zr}_{\mathrm{x}} \mathrm{Pr}_{\mathrm{y}} \mathrm{O}_{2-\mathrm{z}}$ compounds annealed at $700^{\circ} \mathrm{C}$ under air and reduced under $\mathrm{Ar} / 5 \% \mathrm{H}_{2}$ atmosphere $\left(\right.$ Ramp temperature $=5^{\circ} \mathrm{C} / \mathrm{min}$. Total flow $\left.=50 \mathrm{~cm}^{3} / \mathrm{min}\right)$.

For CZP45 and CZP60 compounds, at least $11 \%$ of $\mathrm{Pr}$ remains as tetravalent state after the first reduction step. These two oxides being also the most reducible in this temperature range, their high praseodymium content could explain this result. Finally, CZ (without praseodymium) begins to reduce at a higher temperature $\left(380^{\circ} \mathrm{C}\right)$ than the other ones and only $5 \%$ of cerium is reduced during the first reduction stage between $380^{\circ} \mathrm{C}$ and $455^{\circ} \mathrm{C}$. Therefore, it can be concluded that the introduction of $\mathrm{Pr}$ into the $\mathrm{Ce}_{1-\mathrm{x}} \mathrm{Zr}_{\mathrm{x}} \mathrm{O}_{2-\mathrm{z}}$ networks greatly improves the reducibility for temperatures below $500^{\circ} \mathrm{C}$. By investigating the reducibility of $\mathrm{Ce}_{1-\mathrm{x}-\mathrm{y}} \mathrm{Zr}_{\mathrm{x}} \mathrm{Pr}_{\mathrm{y}} \mathrm{O}_{2-\mathrm{z}}$ with a constant $\mathrm{Zr}$ content of 0.1 (see Figure 5), the reducibility increases with increasing praseodymium levels, both at low temperature and over the entire range of temperature. Taking into account the percentage of oxygen release, the following classification can be proposed regarding the first low temperature reduction step $\left(\mathrm{T}<500^{\circ} \mathrm{C}, \mathrm{Ta}-\right.$ ble 3): $\mathrm{CZP} 10(\% \mathrm{O}=3)<\mathrm{CZP} 30(\% \mathrm{O}=8)<\mathrm{CZP} 45(\% \mathrm{O}=$ $10.5)<\mathrm{CZP} 60(\% \mathrm{O}=13)$. Similarly, the total reducibility follows the same classification (from Table 3): CZP10 $(\% \mathrm{O}=11)$ $<\mathrm{CZP} 30(\% \mathrm{O}=14.5)<\mathrm{CZP} 45(\% \mathrm{O}=15)<\mathrm{CZP} 60(\% \mathrm{O}=$ 20.5).
Table 3: $\Delta \mathrm{O}$ released rate before (initial) and during TGA (TGA, Ar $/ 5 \% \mathrm{H}_{2}$ ) (compounds annealed at $\mathrm{T}=700{ }^{\circ} \mathrm{C}$ under air, see table 1 for oxides formulae).

\begin{tabular}{|c|c|c|c|}
\hline Oxides & $\Delta O$ & $\% O(=\Delta O / 2 * 100)$ & Total \%O \\
\hline \multirow{4}{*}{ CZP33 } & $\Delta O$ inital 0.1 & 5 & \multirow{4}{*}{13} \\
\hline & $0.06\left(320-470^{\circ} \mathrm{C}\right)$ & 3 & \\
\hline & $0.08\left(470-700^{\circ} \mathrm{C}\right)$ & 3 & \\
\hline & $0.04\left(700-900^{\circ} \mathrm{C}\right)$ & 2 & \\
\hline \multirow{4}{*}{$\mathrm{CZ}$} & $\Delta O$ inital 0 & 0 & \multirow{4}{*}{9.5} \\
\hline & $0.04\left(380-500^{\circ} \mathrm{C}\right)$ & 2 & \\
\hline & $0.09\left(500-700^{\circ} \mathrm{C}\right)$ & 4.5 & \\
\hline & $0.06\left(700-900^{\circ} \mathrm{C}\right)$ & 3 & \\
\hline \multirow{4}{*}{ CZP4O } & $\Delta O$ initial 0.1 & 5 & \multirow{4}{*}{14.5} \\
\hline & $0.09\left(305-490^{\circ} \mathrm{C}\right)$ & 4.5 & \\
\hline & $0.06\left(490-700^{\circ} \mathrm{C}\right)$ & 3 & \\
\hline & $0.04\left(700-900^{\circ} \mathrm{C}\right)$ & 2 & \\
\hline \multirow{4}{*}{ CZP10 } & $\Delta O$ inital 0.02 & 1 & \multirow{4}{*}{11} \\
\hline & $0.04\left(310-460^{\circ} \mathrm{C}\right)$ & 2 & \\
\hline & $0.1\left(460-700^{\circ} \mathrm{C}\right)$ & 5 & \\
\hline & $0.06\left(700-900^{\circ} \mathrm{C}\right)$ & 3 & \\
\hline \multirow{4}{*}{ CZP30 } & $\Delta O$ inital 0.06 & 3 & \multirow{4}{*}{14.5} \\
\hline & $0.1\left(305-490^{\circ} \mathrm{C}\right)$ & 5 & \\
\hline & $0.08\left(490-700^{\circ} \mathrm{C}\right)$ & 4 & \\
\hline & $0.05\left(700-900^{\circ} \mathrm{C}\right)$ & 2.5 & \\
\hline \multirow{4}{*}{ CZP45 } & $\Delta \mathrm{O}$ inital 0.05 & 2.5 & \multirow{4}{*}{15} \\
\hline & $0.16\left(300-520^{\circ} \mathrm{C}\right)$ & 8 & \\
\hline & $0.05\left(520-700^{\circ} \mathrm{C}\right)$ & 2.5 & \\
\hline & $0.04\left(700-900^{\circ} \mathrm{C}\right)$ & 2 & \\
\hline \multirow{5}{*}{ CZP60 } & $\Delta O$ initial 0.1 & 5 & \multirow{5}{*}{20.5} \\
\hline & $0.16\left(290-430^{\circ} \mathrm{C}\right)$ & 8 & \\
\hline & $0.09\left(430-540^{\circ} \mathrm{C}\right)$ & 4.5 & \\
\hline & $0.03\left(540-700^{\circ} \mathrm{C}\right)$ & 1.5 & \\
\hline & $0.03\left(700-900^{\circ} \mathrm{C}\right)$ & 1.5 & \\
\hline
\end{tabular}

Starting with $\mathrm{Pr}^{4+} / \mathrm{Pr}^{3+}$ molar ratio determined by magnetic measurements for samples annealed at $\mathrm{T}=700^{\circ} \mathrm{C}$ under air, the $\Delta \mathrm{O}$ released oxygen rate at moderate temperature $\left(300^{\circ} \mathrm{C}\right.$ $500^{\circ} \mathrm{C}$ ) under reducing atmosphere have been estimated (reported on Tables 3 and 1-SI) on the basis of TGA experiments. Thus, it seems clear that the majority of $\operatorname{Pr}^{4+}$ ions is then reduced in a first step (between $300^{\circ} \mathrm{C}$ and $500{ }^{\circ} \mathrm{C}$ ) as clearly illustrated in Figure 5. Only CZP45 containing the highest $\mathrm{Pr}^{4+}$ rate $(81 \%)$ undergoes a reduction of $\mathrm{Pr}^{4+}$ above $500^{\circ} \mathrm{C}$ accompanied by that of the $\mathrm{Ce}^{4+}$ ions. For $\mathrm{CZ}$ and CZP40 compounds (both containing $20 \%$ at. $\% \mathrm{Zr}$ ), the percentage of reducible $\mathrm{Ce}^{4+}$ in the second stage (up to $700{ }^{\circ} \mathrm{C}$ ) is almost identical (about 30\%). As $\mathrm{Zr}$ content increases (CZP33), this reducible $\mathrm{Ce}^{4+}$ level increases, demonstrating the influence of $\mathrm{Zr}$ which allows enhancing the $\mathrm{Ce}^{4+}$ reducibility independently of that of $\mathrm{Pr}^{4+}$ ions. For the same $\mathrm{Ce}$ and $\mathrm{Pr}$ content but when decreasing the $\mathrm{Zr}$ atomic ratio (comparison between CZP40 and CZP45), the two reduction phenomena associated to $\mathrm{Pr}$ and $\mathrm{Ce}$ are well differentiated. For instance, the Pr-rich CZP60 oxide exhibits an interesting behavior with two reduction phenomena occurring at low temperature. The first one occurs between $300^{\circ} \mathrm{C}$ and $450^{\circ} \mathrm{C}$, where about $90 \%$ of $\operatorname{Pr}^{4+}$ ions are reduced, and the next one occurs 
between $450^{\circ} \mathrm{C}$ and $550^{\circ} \mathrm{C}$, which contributes to the reduction of $10 \%$ of remaining $\mathrm{Pr}^{4+}$ and $30 \%$ of $\mathrm{Ce}^{4+}$. Considering a constant $\mathrm{Zr}$ content (for instance $10 \%$ at $\mathrm{Zr}$ in Table 3), the first reduction is initiated at a lower temperature as the $\operatorname{Pr}$ rate is high, confirming that in the presence of $\mathrm{Ce}$ and $\mathrm{Zr}$ atoms, the $\mathrm{Pr}^{4+}$ ions within the fluorine network are highly reducible.

Finally, the increase of $\mathrm{Zr}$ and $\mathrm{Pr}$ concentrations allows raising the $\mathrm{Pr}^{3+}$ rate associated to oxygen vacancies and the $\mathrm{Ce}^{4+}$ reducible rate at low temperature. Thus, the occurrence of large polarizable cations $\left(\mathrm{Pr}^{3+}\right)$ associated to oxygen vacancies and smaller polarizing cations $\left(\mathrm{Zr}^{4+}\right)$ strongly contribute to disturb the local environment of labile oxygen.

Figure 6 shows the $\mathrm{H}_{2}$-TPR profiles of CZ, CZP10, $\mathrm{CZP} 33$ and $\mathrm{CZP} 45$ oxides annealed at $700^{\circ} \mathrm{C}$. The total hydrogen uptakes, calculated from the area measured between $\mathrm{T}=$ $30^{\circ} \mathrm{C}$ and $800^{\circ} \mathrm{C}$ are given in Table 1 -SI. The reduction appears globally lower than within the TGA experiments because of the less reductive setup $\left(1 \% \mathrm{H}_{2}\right.$ for TPR and $5 \% \mathrm{H}_{2}$ for TGA). The reducibility at low temperatures $\left(350^{\circ} \mathrm{C}<\mathrm{T}<500^{\circ} \mathrm{C}\right)$ of $\mathrm{CZP} 10$ is slightly higher than that of $\mathrm{CZ}$ oxide but it is the opposite for $\mathrm{T}>500^{\circ} \mathrm{C}$. The total reducibility of $\mathrm{CZ}$ compound $(497 \mu \mathrm{mol} / \mathrm{g})$ is greater than that of CZP10 oxide, which is $345 \mu \mathrm{mol} / \mathrm{g}$. Two reduction peaks are evidenced in CZP10.

The reduction starts at much lower temperatures, around $250^{\circ} \mathrm{C}$, for CZP33. Two reduction peaks can be clearly distinguished at $440^{\circ} \mathrm{C}$ and around $610^{\circ} \mathrm{C}$, slightly shifted from CZP10 oxide (containing less $\mathrm{Pr}$ and $\mathrm{Zr}$ but more $\mathrm{Ce}$ ).

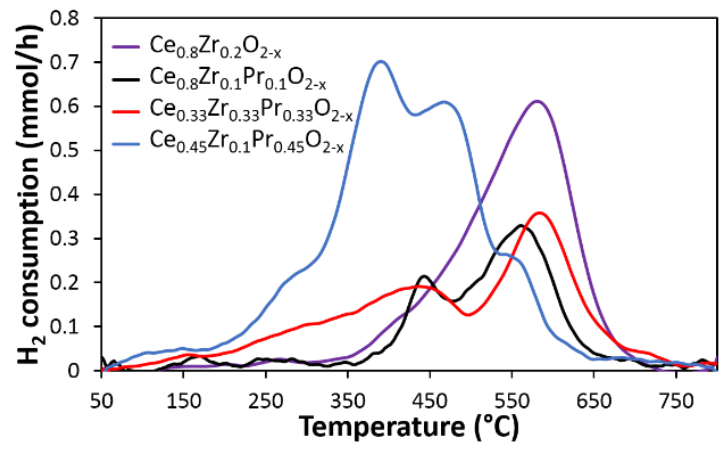

Fig. 6: $\mathrm{H}_{2}-\mathrm{TPR}$ analysis of selected $\mathrm{Ce}_{1-\mathrm{x}-\mathrm{y}} \mathrm{Zr}_{\mathrm{x}} \mathrm{Pr}_{\mathrm{y}} \mathrm{O}_{2-\mathrm{z}}$ complex oxides annealed at $700^{\circ} \mathrm{C}$ under air and reduced under $\mathrm{Ar} / 1 \%$ $\mathrm{H}_{2}$ atmosphere. Ramp temperature $=10^{\circ} \mathrm{C} / \mathrm{min}$. Total flow $=$ $100 \mathrm{~cm}^{3} / \mathrm{min}$.

The total consumption of hydrogen is the same as that of $\mathrm{CZ}$ oxide. On the other hand, its reducibility at low temperatures is much higher. It is therefore jointly the increase in the Pr and $\mathrm{Zr}$ contents which contributes to raise the reducibility at low temperature in agreement with the thermogravimetric analysis presented above.

Finally, this TPR analysis allows identifying the different reduction phenomena in good agreement with the TGA experiments: i) at very low temperatures, the reduction of surface $\operatorname{Pr}^{4+}$ ions may first occur $1,2,3,4,5,6$; ii) from about $300^{\circ} \mathrm{C}$ to $520^{\circ} \mathrm{C}$, two stages of $\mathrm{Pr}^{4+}$ reduction are evidenced on the basis of TGA (first derivative) curves, possibly in link with two different labile oxygen sites within the fluorite network, as discussed in the next section, iii) the TGA curve of CZP60 compound, a Pr-rich compound like CZP45 phase, also reveals the occurrence of two reduction steps between $300^{\circ} \mathrm{C}$ and $500^{\circ} \mathrm{C}$.

\section{4- Discussion around the labile oxygen site on the basis of a statistical approach}

$\mathrm{MO}_{2}$ fluorite can be described as a 3D lattice $\underline{\underline{I}}$ of edge sharing tetrahedrons of the cations surrounding the oxygen ions. Assuming an ideal statistical distribution of the cations in all the compounds under study, we discuss the impact of the local environment of the oxygen on its lability and the reducibility of the compounds. The analysis is based on the results of magnetic measurements, which determine the room temperature oxygen non-stoichiometry after the synthesis under air at $700{ }^{\circ} \mathrm{C}$, and the TGA measurements in a reductive atmosphere, which give its evolution with temperature. As shown in Figure 7 in the cases of CZP60-45-30, the derivatives of the TGA curves highlight several domains and, in the following, we will assume that they represent the activation of some specific oxygen sites depending on their cation environment.

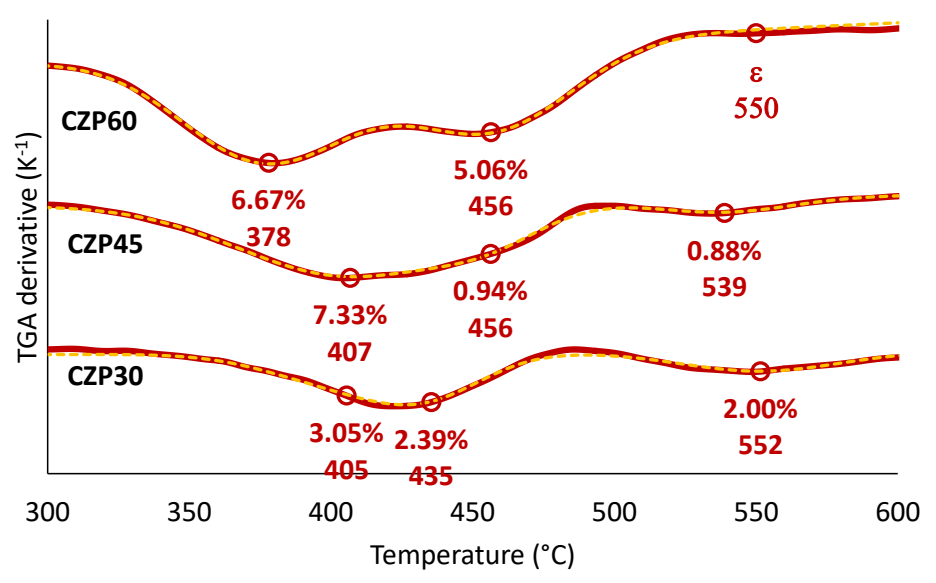

Fig.7: First derivatives of the experimental TGA curves (red curves) of CZP30-45-60 with the three domains of reduction. Open circles point to the mean temperature $\left({ }^{\circ} \mathrm{C}\right)$ as given by a Gaussian fit (yellow dot curves). The associated number of lost oxygen is given relative to 2 .

We focus only on the temperature region upper than $300{ }^{\circ} \mathrm{C}$ (after elimination of water and carbonates adsorbed at the surface) and below $600{ }^{\circ} \mathrm{C}$. For each composition, the TGA curves derivatives are modeled using a simple Gaussian decomposition and we determine a mean temperature, a standard deviation and the associated oxygen loss for each domain (Table 4). For all compounds, at most three domains are visible which 
can globally be grouped depending on the mean activation temperature at $c a .400^{\circ} \mathrm{C}, 440{ }^{\circ} \mathrm{C}$ and $550{ }^{\circ} \mathrm{C}$. We assume that the first mechanism, at low temperature, is the continuation of the depletion observed after the synthesis in air, e.g. the first mechanism for CZP60 deals with the initial loss of 5\% plus the $6.67 \%$ appearing within the first peak at $377^{\circ} \mathrm{C}$, i.e. $11.67 \%$. The idea for the assignment is then to consider the sequential and preferential depletion of some specific oxygen sites depending on their cation environment.

\begin{tabular}{|c|c|c|c|c|c|c|c|}
\hline \multirow[b]{2}{*}{ CZP10" } & \multirow{2}{*}{\begin{tabular}{|l|}
$\begin{array}{l}\text { Initial oxygen non } \\
\text { stoichiometry }\end{array}$ \\
$0.85 \%+\ldots$ \\
\end{tabular}} & \multicolumn{2}{|c|}{$\begin{array}{l}\text { Domain } 1 \\
\bar{T}(\sigma) \text { in }{ }^{\circ} \mathrm{C} \\
\text { and oxygen loss (\%) }\end{array}$} & \multicolumn{2}{|c|}{$\begin{array}{l}\text { Domain } 2 \\
\bar{T}(\sigma) \text { in }{ }^{\circ} \mathrm{C} \\
\text { and oxygen loss (\%) }\end{array}$} & \multicolumn{2}{|c|}{$\begin{array}{l}\text { Domain } 3 \\
\bar{T}(\sigma) \text { in }{ }^{\circ} \mathrm{C} \\
\text { and oxygen loss }(\%)\end{array}$} \\
\hline & & $387(25)$ & $0.68 \%$ & & & $544(39)$ & $1.98 \%$ \\
\hline & Possible environment & \multicolumn{2}{|c|}{$0.96 \% \mathrm{Pr}_{2} \mathrm{CeZr} / \mathrm{PrCeZr}_{2}$} & & & \multicolumn{2}{|c|}{ 3.84\% $\mathrm{Ce}_{2} \mathrm{Zr}_{2} / \mathrm{Pr}_{2} \mathrm{Ce}_{2}$} \\
\hline \multirow[t]{2}{*}{ CZP30" } & $2.48 \%+\ldots$ & $405(26)$ & $3.05 \%$ & $435(20)$ & $2.39 \%$ & $552(28)$ & $2.00 \%$ \\
\hline & Possible environment & \multicolumn{2}{|c|}{ 6.48\% $\mathrm{Pr}_{2} \mathrm{CeZr} / \mathrm{CePr}_{3}$} & \multicolumn{2}{|c|}{ 2.16\% $\mathrm{PrCeZr}_{2} / \mathrm{Ce}_{2} \mathrm{Zr}_{2}$} & \multicolumn{2}{|c|}{ 2.16\% $\mathrm{PrCeZr}_{2} / \mathrm{Ce}_{2} \mathrm{Zr}_{2}$} \\
\hline \multirow[t]{2}{*}{$C Z P 45^{* 4}$} & $2.15 \%+\ldots$ & $407(40)$ & $7.33 \%$ & $456(19)$ & $0.94 \%$ & $539(24)$ & $0.88 \%$ \\
\hline & Possible environment & \multicolumn{2}{|c|}{$10.94 \% \mathrm{Pr}_{2} \mathrm{CeZr} / \mathrm{PrCl}_{2} \mathrm{Zr}$} & \multicolumn{2}{|c|}{ 2.43\% PrCeZr $_{2}$} & \multicolumn{2}{|c|}{$1.22 \% \mathrm{Ce}_{2} \mathrm{Zr}_{2} / \mathrm{Pr}_{2} \mathrm{Zr}_{2}$} \\
\hline \multirow[t]{2}{*}{ CZP60 ${ }^{\circ}$} & $5.00 \%+\ldots$ & $378(30)$ & $6.67 \%$ & $456(29)$ & 5.06 & 550 & $\varepsilon$ \\
\hline & Possible environment & \multicolumn{2}{|c|}{$12.96 \% \mathrm{Pr}_{2} \mathrm{CeZr} / \mathrm{Pr}_{4}$} & \multicolumn{2}{|c|}{ 6.48\% $\mathrm{PrCe}_{2} \mathrm{Zr} / \mathrm{PrCe}_{3}$} & \multicolumn{2}{|c|}{$0.12 \% \mathrm{CeZl}_{3}, 0.54 \% \mathrm{Ce}_{2} \mathrm{Zr}_{2}$} \\
\hline \multirow[t]{2}{*}{$\mathrm{CZP} 40^{\prime}$} & $4.90 \%+\ldots$ & $401(41)$ & $3.93 \%$ & 440 (22) & $0.81 \%$ & $536(44)$ & $2.37 \%$ \\
\hline & Possible environment & \multicolumn{2}{|c|}{$10.24 \% \mathrm{Pr}_{3} \mathrm{Zr} / \mathrm{Ce}_{3} \mathrm{Zr}$} & \multicolumn{2}{|c|}{$1.28 \% \mathrm{PrZr}_{3} / \mathrm{CeZr}_{3}$} & \multicolumn{2}{|c|}{$3.84 \% \mathrm{Ce}_{2} \mathrm{Zr}_{2} / \mathrm{Pr}_{2} \mathrm{Zr}_{2}$} \\
\hline CZP33' & $4.67 \%+\ldots$ & $376(34)$ & $1.54 \%$ & $417(19)$ & $1.04 \%$ & $556(36)$ & $4.06 \%$ \\
\hline
\end{tabular}

Table 4: Initial oxygen non-stoichiometry deduced from magnetic measurement and oxygen losses in three various domains. We assume that the initial oxygen non-stoichiometry and the first oxygen loss are part of the first domain. The possible cation environments are determined best matching each domain size with the occurrence of a specific environment in each compound. All solutions are given.

For each possible environment, its proportion in each compound is calculated using a binomial law: $p_{i}\left(N_{C e}, N_{P r}, N_{Z r}\right)=$ $\left(\begin{array}{c}4 \\ N_{C e}\end{array}\right) a^{N_{C e}}\left(\begin{array}{c}4-N_{C e} \\ N_{P r}\end{array}\right) b^{N_{P r}} c^{4-N_{C e}-N_{P r}}$ with $\sum_{i} p_{i}=1$; here $N_{A}$ denotes the amount of each cation in the oxygen environment for a composition $C e_{a} \operatorname{Pr}_{b} Z r_{c} O_{2-\delta}$ with $a+b+c=1$; obviously, $p_{i}$ shows some symmetry depending on the composition and $N_{A}$, then some sites have the same existence probability (see Table S2). We assume that each reduction mechanism is associated with a specific oxygen departure corresponding to a peculiar $\mathrm{OM}_{4}$ tetrahedron: for each composition, we match the oxygen loss in the domains with the closest proportion $p_{i}$; in a first approximation we discard all effects related to clusterization. For example, using again the case of CZP60, we obtain for the first mechanism the closest $p_{i}=12.96 \%$ for both $P r_{2} C e_{1} Z r_{1}$ and $\mathrm{Pr}_{4}$ and we associate the oxygen release to one of these two sites. Table 4 gathers all the results of these calculations for all compounds.

It is easily seen that some trends emerge, especially for these compounds with a constant Zr rate at 10\% (CZP10, 30, 45, 60). In this series, among the possible solutions the first peak consistently relates to a $\mathrm{Pr}_{2} C \mathrm{e}_{1} Z r_{1}$ environment, the second one to $\operatorname{Pr}_{1} C e_{1 \text { or } 2} Z r_{2}$ or 1 and the last one systematically to $C e_{2} Z r_{2}$. This progression obviously obeys some logic. Following the argument given in the magnetic measurements section, $\mathrm{Pr}^{4+}$ is the most reducible cation and it is both the majority in the environment involved in the first mechanism and it is also in sufficient amount to compensate for the departure of one oxygen: $O C e_{1}^{4+} \mathrm{Pr}_{2}^{4+} \mathrm{Zr}_{1}^{4+} \rightarrow \square C e_{1}^{4+} \mathrm{Pr}_{2}^{3+} \mathrm{Zr}_{1}^{4+}$. As $\mathrm{Pr}^{4+}$ is consumed, its involvement in the reduction process decreases and the site associated with the second mechanism is impoverished with praseodymium (and even fully absent in the case of CZP10): $O C e_{1 \text { or } 2}^{4+} \mathrm{Pr}_{1}^{4+} \mathrm{Zr}_{2}^{4+}$ or $1 \rightarrow \square C e_{1 \text { or } 2}^{4+} \mathrm{Pr}_{1}^{3+} \mathrm{Zr}_{2}^{4+}$ or 1 ; we note here that the reaction is to double depending on the involvement of the cerium cation in the reduction process at this stage. Finally, when all $\mathrm{Pr}^{4+}$ is consumed, or at least when no more is reducible, a mechanism implying only cerium ions activates: $\mathrm{OCe}_{2}^{4+} \mathrm{Zr}_{2}^{4+} \rightarrow \square \mathrm{Ce}_{2}^{3+} \mathrm{Zr}_{2}^{4+}$. Several points can be highlighted from the analysis at constant $\mathrm{Zr}$ rate (10\%): (i) although it is quite simple model to compare the amount of available environments to the amount of oxygen leaving the structure, it looks able to evidence several systematic features; (ii) the domains are clearly identified and their mean temperature barely evolve from a compound to the next one; (iii) the role of $\mathrm{Pr}^{4+}$ in the reduction process, and especially at low temperature, agrees well with the assumption given upper in the magnetic measurements section concerning the higher reducibility of praseodymium; (iv) at least one zirconium ion consistently appears in the environment of the labile oxygen; (v) it is also interesting to note that while there is most often only one $\mathrm{Zr}$ atom in the environments implying also the Pr cations, there are two when only the $\mathrm{Ce}$ cations is involved $\left(\mathrm{Ce}_{2} \mathrm{Zr}_{2}\right)$. The presence of some $\mathrm{Zr}^{4+}$ in the environments of the labile oxygen is actually not surprising: there can be a steric effect with a larger volume given to the host that may enhance its mobility; it is strongly desymmetrizing the polyhedron and probably destabilizing its host; it is highly polarizing and it is likely to stabilize the reduced cations.

These observations can be used to address the more complex cases of the compounds with constant $\mathrm{Pr} / \mathrm{Ce}$ ratio (CZP33, 40, 45), especially if we remark that the same domains exist in this series (Table 4). We first note for CZP33 that due to the parity in the cations proportion and the symmetry in $\mathrm{N}_{\mathrm{A}}$, number of environments have the same probability of existence (all three with only one specie in the close surrounding at $1.23 \%$, all six $1+3$ environments at $4.94 \%$, all three $2+2$ at $7.41 \%$ and all three $2+1+1$ at $14.81 \%$ ) what makes a direct discrimination between active sites only on the basis of statistics less obvious. The first domain $(4.67 \%+1.54 \%=6.21 \%)$ could be associated to $\mathrm{OPr}_{3} \mathrm{Zr}$ following the previous analysis whereas the second and third domains could respectively correspond to $\mathrm{OPr}_{4}(1.04 \%)$ and $\mathrm{OCeZr}_{3}(4.06 \%)$. Finally in $\mathrm{Ce}_{2} \mathrm{Zr}_{2} \mathrm{O}_{7} / \mathrm{Pr}_{2} \mathrm{Zr}_{2} \mathrm{O}_{7}$ pyrochore-type phases , a superstructure of fluorite-type network (depicted on Figure S5) obtained after reduction at $\mathrm{T}=500^{\circ} \mathrm{C}-600^{\circ} \mathrm{C}$ under $\mathrm{Ar} / 5 \% \mathrm{H}_{2}$ of $\mathrm{Ce}_{2} \mathrm{Zr}_{2} \mathrm{O}_{8}{ }^{33}$ oxide, the oxygen vacancy crystallographic site corresponds precisely to $\square \mathrm{CeZr}_{3}$.

Taking into account this statistical approach and based on first principles DFT calculations, the analysis of activation energies of oxygen vacancy migration in these complex oxides is in progress.

\section{5- Transport properties measured on dense pellets and in- fluence of the composition}

The thermal variation of the total conductivity, measured by the four-point probe method on dense pellets annealed at $\mathrm{T}=1400^{\circ} \mathrm{C}$ under air, is shown in Figure 8 for $\mathrm{CZ}$ and $\mathrm{CZP} 10$ - 
30-45. The total conductivity values at room temperature, $\mathrm{T}=230^{\circ} \mathrm{C}$ and $\mathrm{T}=430^{\circ} \mathrm{C}$ are given in Table $5 . \mathrm{CZ}$ is strongly insulating and its conductivity could not be measured below $300^{\circ} \mathrm{C}$. CZP10 also exhibits a typical insulating behavior with $\sigma$ ranging from $\mathrm{ca} 10^{-9}$ to $10^{-4} \mathrm{~S} / \mathrm{cm}$ from $\mathrm{RT}$ to $1000{ }^{\circ} \mathrm{C}$. On the other hand, CZP30 and especially CZP45 compounds, which are more Pr-rich, exhibit higher conductivities what is obviously related to some hopping phenomenon involving the localized $4 \mathrm{f}$ orbital or the more extended $5 \mathrm{~d}$ orbital of $\mathrm{Pr}$ atoms ${ }^{34}$

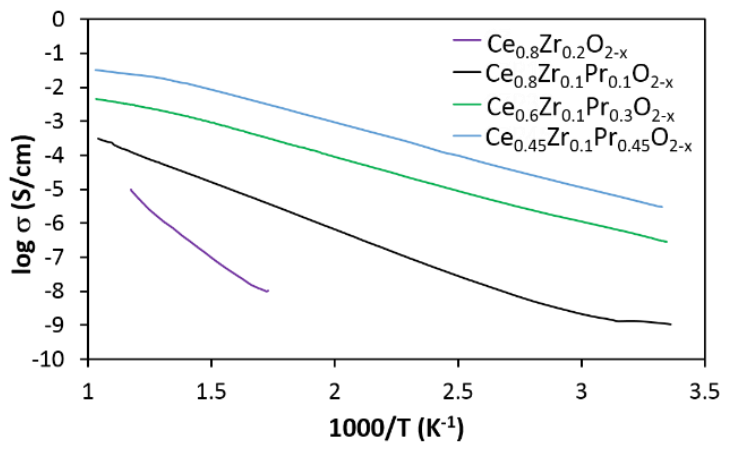

Fig. 8: Thermal variation of the total (ionic + electronic) conductivity measured by four probes method under air between $300 \mathrm{~K}$ and $1000 \mathrm{~K}$ for various compositions.

Table 5: Total conductivity values $(\mathrm{S} / \mathrm{cm})$ at various temperatures for $\mathrm{Ce}_{1-\mathrm{x}-\mathrm{y}} \mathrm{Zr}_{\mathrm{x}} \mathrm{Pr}_{\mathrm{y}} \mathrm{O}_{2-\mathrm{z}}$ compounds (see table 1 for oxides formulae) measured by four-probe methods. The error bars of conductivity values and deduced activation energies are less than $1 \%$.

\begin{tabular}{|c|c|c|c|}
\hline Oxide & $\begin{array}{c}\text { Total } \\
\text { conductivity at } \\
\mathrm{RT}(\mathrm{S} / \mathrm{cm})\end{array}$ & $\begin{array}{c}\text { Total conductivity } \\
\text { at } 230^{\circ} \mathrm{C}(\mathrm{S} / \mathrm{cm})\end{array}$ & $\begin{array}{c}\text { Total conductivity } \\
\text { at } 430^{\circ} \mathrm{C}(\mathrm{S} / \mathrm{cm})\end{array}$ \\
\hline CZ & - & $5^{*} 10^{-8}$ & $2.3^{*} 10^{-7}$ \\
\hline CZP10 & $1^{*} 10^{-9}$ & $6.6^{*} 10^{-7}$ & $2.6^{*} 10^{-5}$ \\
\hline CZP30 & $3^{*} 10^{-7}$ & $8.8^{*} 10^{-5}$ & $1.2^{*} 10^{-3}$ \\
\hline CZP45 & $3^{*} 10^{-6}$ & $9.3^{*} 10^{-4}$ & $1.2^{*} 10^{-2}$ \\
\hline
\end{tabular}

It is worth noting that for both CZP30 and CZP 45, the $\log (\sigma)=\mathrm{f}(1000 / \mathrm{T})$ curves evidence two distinct regimes with a clear break in the slopes at $c a 500{ }^{\circ} \mathrm{C}$. For both compounds, the associated activation energies are $0.38 \mathrm{eV}$ below $500{ }^{\circ} \mathrm{C}$ and $0.17 \mathrm{eV}$ above $500{ }^{\circ} \mathrm{C}$. Such significant reduction in the activation energy suggests a change either in the nature and/or the amount of charge carriers. A change of the transport mechanism can also be expected. The thermal variation of the Seebeck coefficient $\alpha$ (Figure 9) measured on a sintered pellet of CZP45 oxide (calcinated at $1400^{\circ} \mathrm{C}$ under air) reveals this change with a change in the nature of the charge carriers at $520^{\circ} \mathrm{C}$. At low temperatures, when $\mathrm{Pr}^{4+} / \mathrm{Pr}^{3+}>1, \alpha$ is negative (n-type semiconductor). When the temperature is raised up to $400{ }^{\circ} \mathrm{C}$, the reduction of $\mathrm{Pr}^{4+}$ to $\mathrm{Pr}^{3+}$ begins and holes become the majority charge carriers at $520{ }^{\circ} \mathrm{C}$ when the thermopower becomes positive. The low temperature behavior can be seen like an intraspecy charge hopping with a simple charge transfer equilibrium as $\mathrm{Pr}^{4+}+\mathrm{Pr}^{3+}$ $\leftrightarrow \operatorname{Pr}^{3+}+\operatorname{Pr}^{4+}$. On the other hand, at high temperature, both this equilibrium and an interspecies mechanism implying holes transfer from the $2 \mathrm{p}$ oxygen band (valence band) like $\mathrm{Pr}^{4+}+\mathrm{O}^{2-}$ $\leftrightarrow \mathrm{Pr}^{3+}+\mathrm{O}^{-}$can be also considered.

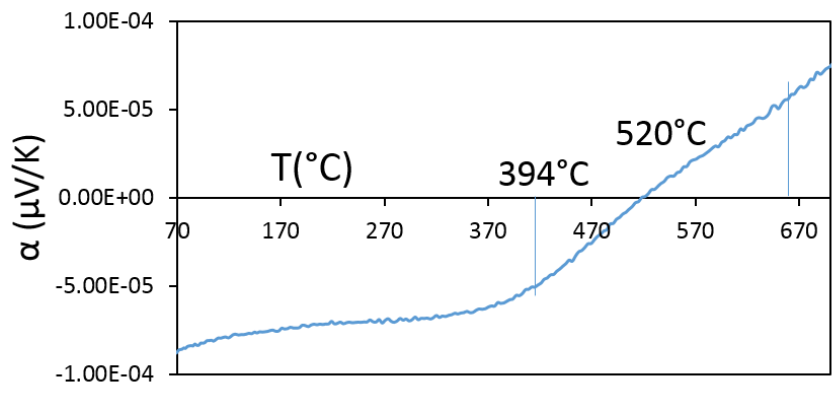

Fig. 9: Thermal variation of the Seebeck coefficient under air of $\mathrm{Ce}_{0.45} \mathrm{Zr}_{0.1} \mathrm{Pr}_{0.45} \mathrm{O}_{2-\mathrm{x}}$ pellet sintered under air at $1400^{\circ} \mathrm{C}$.

An energy band diagram ${ }^{34}$ involving the $2 \mathrm{p}$ oxygen band, the $4 \mathrm{f}\left(\mathrm{Pr}^{4+} / \mathrm{Pr}^{3+}\right)$ levels and the $5 \mathrm{~d}(\mathrm{Ce} / \mathrm{Pr})$ band is schemed in Figure 10.
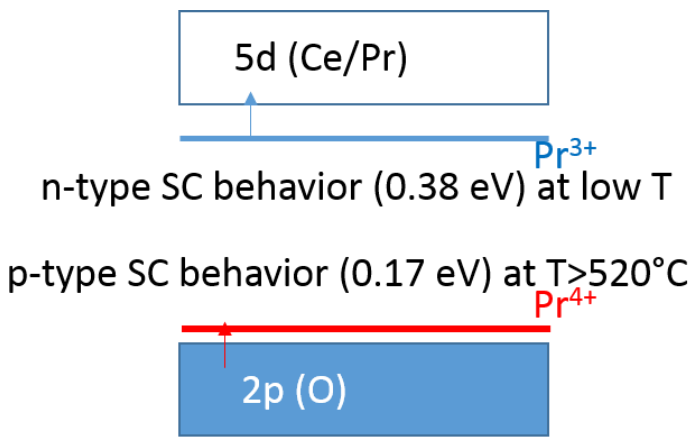

Fig. 10: Band diagram of $\mathrm{Ce}_{0.45} \mathrm{Zr}_{0.1} \mathrm{Pr}_{0.45} \mathrm{O}_{2-\mathrm{x}}$ complex oxide deduced from the thermal evolution of Seebeck coefficient and total conductivity.

The beginning of the reduction process at $400{ }^{\circ} \mathrm{C}$ is confirmed with a TGA experiment carried out under air (Figure S6) using a temperature ramp of $5^{\circ} \mathrm{C} / \mathrm{min}$, from room temperature up to $800^{\circ} \mathrm{C}$ on a pellet sintered under air at $1400^{\circ} \mathrm{C}$. Fixing $\mathrm{Pr}^{4+} / \mathrm{Pr}^{3+}=1$ at $520{ }^{\circ} \mathrm{C}$ allows calculating the initial $\mathrm{Pr}^{4+}$ content in the pellet at $61 \%$, i.e. much lower than after a synthesis at only $700{ }^{\circ} \mathrm{C}$. This highlights not only the large range of possible composition but also the high oxygen storage capacity of the compound. Figure S6 also illustrates this point under air and $\mathrm{Ar} / 5 \% \mathrm{H}_{2}$ with plots of the evolution of Pr ions content depending on their valence state (deduced from TGA experiments). Within the same approach, Figure S7 compares all compounds in this study (under $\mathrm{Ar} / 5 \% \mathrm{H}_{2}$ ), highlighting again the key role of Pr substitution in the low temperature redox process.

\section{$6-{ }^{18} \mathrm{O} /{ }^{16} \mathrm{O}$ exchange (IEDP-SIMS) and relaxation conductiv- ity measurement on dense pellets}

Isotopic Exchange Depth Profile (IEDP) measurements have been performed on dense pellets with CZ, CZP10, CZP30 and CZP45 compositions, after isotopic oxygen exchanges performed at $\mathrm{T}=400^{\circ} \mathrm{C}$ during $1 \mathrm{~h}$. The oxygen diffusion depth values were initially unknown and the depth profile method (which focuses on few micrometers of analyses only) was first used. The normalized oxygen concentration profiles recorded on $\mathrm{CZ}$ and $\mathrm{CZP} 10$ pellets are plotted in Figure S8. The 
profile recorded on $\mathrm{CZ}$ pellet evidences that oxygen has diffused on a very small distance (less than $1 \mu \mathrm{m}$ ), while for CZP10, the diffusion is about 4 times larger. At the end of the oxygen profile the natural ${ }^{18} \mathrm{O}$ abundancy is reached. In both cases, the oxygen concentration at depth $=0 \mu \mathrm{m}$ (surface) is very low (around $1.5 \times 10^{-2}$ ), then from a qualitative point of view, the oxygen surface exchange coefficient is very low. For CZP30 and CZP45 pellets, the oxygen concentration is almost linear as a function of depth (not shown). This means that the diffusion depth is larger than $5 \mu \mathrm{m}$ and thus that the depth profile method is not adapted. Fitting the experimental data with the Crank model $^{25}$ leads to determine the $\mathrm{D}^{*}$ and $\mathrm{k}^{*}$ coefficients on $\mathrm{CZ}$ and $\mathrm{CZP} 10$ oxides at $400^{\circ} \mathrm{C}$ (Table 6). Both materials can be considered as bad ionic oxygen conductors with low oxygen surface exchange coefficients.

Table 6: $\mathrm{D}_{\text {chem }}, \mathrm{D}^{*}, \mathrm{k}_{\text {chem }}$ and $\mathrm{k}^{*}$ coefficients determined on $\mathrm{CZ}$, CZP10 and CZP45 materials at different temperature.

\begin{tabular}{ccccc}
\hline Composition & $\mathrm{D}_{\text {chem }}\left(\mathrm{cm}^{2} / \mathrm{s}\right)$ & $\mathrm{D}^{*}\left(\mathrm{~cm}^{2} / \mathrm{s}\right.$ & $\mathrm{k}_{\text {chem }}(\mathrm{cm} / \mathrm{s})$ & $\mathrm{k}^{*}(\mathrm{~cm} / \mathrm{s})$ \\
\hline $\mathrm{CZ}\left(400^{\circ} \mathrm{C}\right)$ & & $1.2 \times 10^{-13}$ & & $8.4 \times 10^{-11}$ \\
$\mathrm{CZP} 10\left(400^{\circ} \mathrm{C}\right)$ & & $1 \times 10^{-11}$ & & $9 \times 10^{-10}$ \\
$\mathrm{CZP45}\left(20^{\circ} \mathrm{C}\right)$ & & $4 \times 10^{-10}$ & & $5 \times 10^{-10}$ \\
$\mathrm{CZP45}\left(400^{\circ} \mathrm{C}\right)$ & $2 \times 10^{-6}$ & $\begin{array}{c}1.5 \times 10^{-8} \\
\text { (calculated) }\end{array}$ & $5 \times 10^{-5}$ & \\
$\mathrm{CZP45}\left(700^{\circ} \mathrm{C}\right)$ & $6 \times 10^{-6}$ & $\begin{array}{c}4.6 \times 10^{-8} \\
\text { (calculated) }\end{array}$ & $4 \times 10^{-4}$ & \\
\hline
\end{tabular}

In order to obtain the oxygen diffusion profile on a CZP45 pellet, the line scan analysis method has been used. The preliminary oxygen isotopic exchange was performed at $\mathrm{T}=500^{\circ} \mathrm{C}$ during 30 minutes. The result is plotted on Figure 11 and is unexpected: instead of the usual progressive decrease of the oxygen concentration from the surface to the bulk, a "reverse" profile is observed, with a larger oxygen concentration in the center of the pellet compared to a value about 10 times lower on the surface.

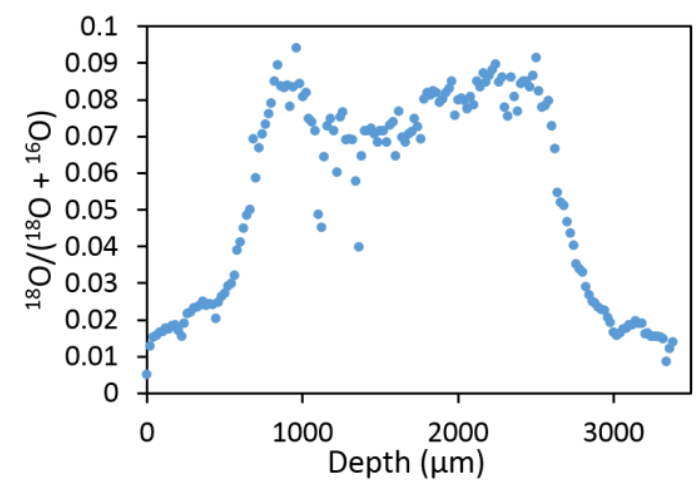

Fig. 11: Normalized oxygen concentration profile recorded on dense pellet with $\mathrm{Ce}_{0.45} \mathrm{Zr}_{0.1} \mathrm{Pr}_{0.45} \mathrm{O}_{2-\mathrm{x}}$ composition, after a preliminary ${ }^{18} \mathrm{O}$ exchange performed at $\mathrm{T}=500^{\circ} \mathrm{C}$ during $30 \mathrm{~min}$.

Experiments were double checked first using the same SIMS device and then using two different devices; the data are perfectly reproducible. In the center of the probed edge, the oxygen concentration is quite low, however 50 times larger than the natural ${ }^{18} \mathrm{O}$ abundancy. At this stage, one can then conclude that CZP45 oxide is a good oxygen ionic conductor, since ${ }^{18} \mathrm{O}$ crossed the entire thickness of the pellet (about $3 \mathrm{~mm}$ ) in only $30 \mathrm{~min}$. Occurrences of oxygen diffusion across mechanical failures of the pellet are discarded, because in that case huge increases of the oxygen concentration would be observed and only limited thicknesses (few micrometers of the failures) would be concerned. A hypothesis to explain the results stands in the one month delay between the isotopic exchange and the profile recording (because of restricted access to the SIMS device): if the oxygen diffusion coefficient is not zero at room temperature, then, before the measurement, an ${ }^{18} \mathrm{O}$ "retro-diffusion" process can occur from the bulk towards the surface We have modeled the "reverse" profile assuming that ${ }^{18} \mathrm{O}$ was diffusing at $20^{\circ} \mathrm{C}$ during one month and the order of magnitude of the $\mathrm{D}^{*}$ and $\mathrm{k}^{*}$ coefficients was determined, i.e. $\mathrm{D}^{*}{ }_{\mathrm{CZP} 45} \sim 4.10$ ${ }^{10} \mathrm{~cm}^{2} . \mathrm{s}^{-1}$ and $\mathrm{k}^{*} \mathrm{CZP45} \sim 5.10^{-10} \mathrm{~cm} \cdot \mathrm{s}^{-1}$ (Table 6). Both values are high as compared to known room temperature data. At the end of this first part it's only possible to conclude that CZP45 is a good ionic conductor.

Electronic conductivity relaxation measurements have also been performed to get more information on the CZP45 sample. The same pellet was used for several measurements at different temperature. The experimental profiles as well as the models are plotted for the experiments performed at 400 and $700^{\circ} \mathrm{C}$. As expected, the electronic conductivity decreases when changing the atmosphere from air to argon, in agreement with the lessening of the charge carrier concentration. The profile, represented on Figure S9, can be globally modeled using the solution of the diffusion equation given by $\mathrm{Crank}^{25}$, meaning that the experimental process is governed both by the surface exchange and the oxygen diffusion phenomena. At low temperature $\left(400^{\circ} \mathrm{C}\right)$, the model is in good agreement with the experimental data, while there is more discrepancy at high temperature $\left(700^{\circ} \mathrm{C}\right)$. Such difference may arise from the experimental conditions during which the applied oxygen partial pressure step $\left(10^{-1}\right.$ (air) $\sim 10^{-5}$ (argon)) is probably slightly too strong, and the expected linear evolution of the measured conductivity as a function of the oxygen concentration is not fully ensured. However, an order of magnitude of both $\mathrm{D}_{\text {chem }}$ and $\mathrm{k}_{\text {chem }}$ has been obtained at $\mathrm{T}=400$ and $700{ }^{\circ} \mathrm{C}$ and the results are gathered in Table 6 . These results evidenced that CZP45 oxide is a very good oxygen ionic conductor even at $400^{\circ} \mathrm{C}$. D* and $\mathrm{k}^{*}$ coefficients are for instance comparable to the ones which can be extrapolated from the high temperature values determined on the best SOFC cathode materials ${ }^{35,36}$. D* and $\mathrm{k}^{*}$ coefficients largely increase when the temperature is increased from 400 to $700^{\circ} \mathrm{C}$. The comparison of the $\mathrm{D}_{\text {chem }}$ and $\mathrm{D}^{*}$ coefficients is possible using the thermodynamic factor $\gamma$ given by the relations:

$$
\mathrm{D}^{*}=\mathrm{D}_{\text {chem }} / \gamma \text { and } \gamma=\mathrm{d} \ln \left(\mathrm{pO}_{2}\right) / 2 \mathrm{~d} \ln \left(\mathrm{C}_{\mathrm{o}}\right)
$$

where $\mathrm{C}_{\mathrm{o}}$ is the oxygen concentration in the material. It was determined by TGA measurements as a function of temperature, either under air and argon, leading to determine $\gamma \sim 130$. The corresponding calculated $\mathrm{D}^{*}$ coefficients are given in Table 6 . The evolution of $\log \left(\mathrm{D}^{*}\right)$ vs. $1000 / \mathrm{T}$ is plotted in Figure 12 for the measurements performed at three temperatures using either ${ }^{18} \mathrm{O} /{ }^{16} \mathrm{O}$ exchange or relaxation conductivity measurement. A typical temperature activated process is evidenced with $\mathrm{E}_{\mathrm{a}} \approx 37 \mathrm{meV}$. It would be necessary to get additional measurements, especially considering various oxygen partial pressure. 
However this study leads to get quite accurate ionic diffusion data for CZP45 oxide and to conclude without any doubt that this material is a very good oxygen conductor, in particular in the low temperature range.

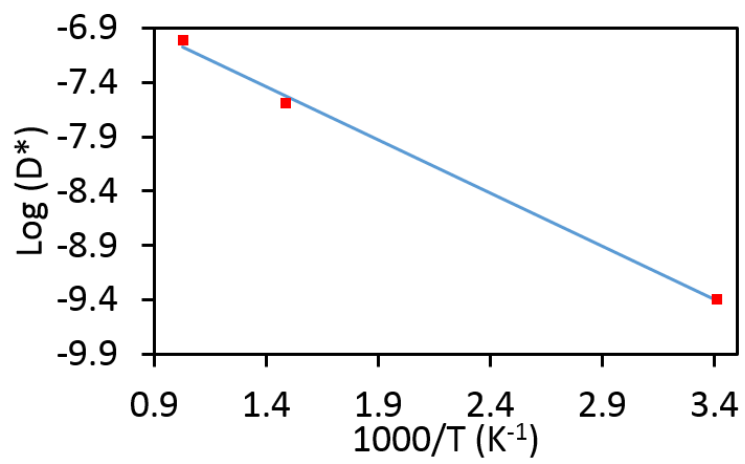

Fig.12: Thermal evolution of $\mathrm{D}^{*}$ oxygen tracer self-diffusion coefficient of $\mathrm{Ce}_{0.45} \mathrm{Zr}_{0.1} \mathrm{Pr}_{0.45} \mathrm{O}_{2-\mathrm{x}}$ oxide.

\section{CONCLUSION}

Several compositions were carefully selected, then investigated in details in the pseudo-ternary $\mathrm{CeO}_{2}-\mathrm{ZrO}_{2}-\mathrm{PrO}_{\mathrm{x}}$ phase diagram. We focused on two series either at constant $\mathrm{Zr}$ content $(10 \%)$ or equal $\mathrm{Ce}$ and Pr content. We show that the thermal stability of these materials is ensured up to about $\mathrm{T}=1400^{\circ} \mathrm{C}$. We globally observe that the higher the $\mathrm{Zr}$ content, the lower the $\operatorname{Pr}^{4+}$ rate. At 10 molar\% $\mathrm{Zr}$, the $\operatorname{Pr}^{4+}$ rate fixes around $66 \%$, like in $\operatorname{Pr}_{6} \mathrm{O}_{11}$, except for $\mathrm{Ce}_{0.45} \mathrm{Zr}_{0.1} \operatorname{Pr}_{0.45} \mathrm{O}_{2-\mathrm{x}}$ (CZP45) which exhibits the highest $\operatorname{Pr}^{4+}$ rate peaking at $81 \%$ just after annealing at $\mathrm{T}=700^{\circ} \mathrm{C}$ under air. The presence of $\mathrm{Pr}$, more reducible than $\mathrm{Ce}$, globally shifts the redox process at low temperature. This is particularly visible for compositions with high $\mathrm{Pr}$ content. The presence of $\mathrm{Zr}$ appears to enhance the $\mathrm{Ce}$ reducibility and to decrease the $\mathrm{Ce}^{4+}$ reduction temperature. For oxides containing as much $\mathrm{Ce}$ as $\mathrm{Pr}$, such as CZP45, the $\mathrm{Pr}^{4+}$ reduction first occurs, followed by that of $\mathrm{Ce}^{4+}$ at higher temperature. Furthermore, the increase of $\mathrm{Pr}$ content $\left(\mathrm{Ce}_{0.3} \mathrm{Zr}_{0.1} \mathrm{Pr}_{0.6} \mathrm{O}_{2-\mathrm{x}}=\mathrm{CZP} 60\right)$ also allows enhancing the $\mathrm{Ce}^{4+}$ reducibility at low temperature. Intra-atomic charge transfer equilibria such as $\mathrm{Pr}^{4+}+\mathrm{Pr}^{3+} / \mathrm{Ce}^{3+} \leftrightarrow \mathrm{Pr}^{3+}+\mathrm{Pr}^{4+} / \mathrm{Ce}^{4+}$ and $\mathrm{Pr}^{4+} / \mathrm{Ce}^{4+}$ $+\mathrm{O}^{2-} \leftrightarrow \mathrm{Pr}^{3+} / \mathrm{Ce}^{3+}+\mathrm{O}^{-}$should contribute to the reducible $\mathrm{Pr}^{4+} / \mathrm{Ce}^{4+}$ regulation rate in the $\mathrm{CZP}$ series. $\mathrm{The}^{\mathrm{Pr}^{4+} / \mathrm{Ce}^{4+} \mathrm{re}-}$ duction step can be systematically associated to an oxygen release and especially to the most labile oxygen environments.

The most probable labile oxygen sites, selected on the basis of a multinomial law that follows the released oxygen rate during the first annealing under air at $\mathrm{T}=700^{\circ} \mathrm{C}$ and in addition during the first reduction step under $\mathrm{Ar} / \mathrm{H}_{2}\left(\mathrm{~T}<500^{\circ} \mathrm{C}\right)$ may contain systematically one $\mathrm{Zr}$ atom, two $\mathrm{Pr}$ and one $\mathrm{Ce}$ atoms as first neighbors. The combination of two various rare earths $(\mathrm{Ce} / \mathrm{Pr})$ with various valences and polarizabilities and in addition one $\mathrm{Zr}^{4+}$ as smaller and more polarizing cation should contribute to a strong distortion of the oxygen tetrahedral sites. Then, the oxygen departure should be followed by the complete $\operatorname{Pr}^{4+}$ reduction on this specific site: $O C e_{1}^{4+} \mathrm{Pr}_{2}^{4+} \mathrm{Zr}_{1}^{4+} \rightarrow \square C e_{1}^{4+} \mathrm{Pr}_{2}^{3+} \mathrm{Zr}_{1}^{4+}$. As the Ce/Pr atomic ratio is equal to 1 with a low $\mathrm{Zr}$ content
(CZP45 versus CZP60 and CZP30), the $\mathrm{Pr}^{4+}$ amount of the pristine material before reduction remains the highest. The two main charge transfer equilibria, $\mathrm{Pr}^{3+}+\mathrm{Ce}^{4+} \leftrightarrow \mathrm{Pr}^{4+}+\mathrm{Ce}^{3+}$ and $\mathrm{Ce}^{3+}+\mathrm{O}^{-} \leftrightarrow \mathrm{Ce}^{4+}+\mathrm{O}^{2-}$ in the vicinity of the most labile oxygen $\left(\mathrm{OZrPr}_{2} \mathrm{Ce}\right.$ in $\left.\mathrm{CZP} 45\right)$ should explain such a behavior in order to maintain a high level of $\mathrm{Pr}^{4+}$. As mentioned in the introductive part, the stabilization of $\mathrm{Pr}^{4+} / \mathrm{Pr}^{3+}$ mixed valences is associated with the creation of oxygen vacancies in the $\operatorname{Pr}_{1-\mathrm{x}} \mathrm{Zr}_{\mathrm{x}} \mathrm{O}_{2-\mathrm{y}}$ series $(0.02<x<0.5)$ and the local environment is strongly affected by the presence of $\mathrm{Pr}^{3+}$ as well as the formation of oxygen vacancies in the vicinity of $\mathrm{Zr}$ atom ${ }^{14}$. In the $\mathrm{CeO}_{2}-\mathrm{ZrO}_{2}-$ $\mathrm{PrO}_{\mathrm{x}}$ phase diagram, the redox properties are indeed related to the $\mathrm{O} / \mathrm{Zr}$ local environments.

Pr-poor compounds are insulating (CZ, CZP10) but high Pr content (CZP30, CZP45, CZP60) enhances the electrical conductivity and the materials become rather good semiconductors with lower activation energies. Two temperature domains are evidenced from electronic transport properties with at low temperature, a n-type conduction $\left(\mathrm{E}_{\mathrm{a}}=0.38 \mathrm{eV}\right)$ and at high temperature $\left(>520{ }^{\circ} \mathrm{C}\right)$ a p-type behavior $\left(\mathrm{E}_{\mathrm{a}}=0.17 \mathrm{eV}\right)$. The change of the nature of charge carriers is related to the partial reduction of $\operatorname{Pr}^{4+}$ ions under air starting at $\mathrm{T}=400^{\circ} \mathrm{C}$. Then two charge transfer equilibria, $\operatorname{Pr}^{3+}+\operatorname{Pr}^{4+} \leftrightarrow \operatorname{Pr}^{4+}+\operatorname{Pr}^{3+}$ (e electron transport) and $\mathrm{Pr}^{4+}+\mathrm{O}^{2-} \leftrightarrow \mathrm{Pr}^{3+}+\mathrm{O}^{-}\left(\mathrm{h}^{+}\right.$holes transport) may occur at low and high temperature, respectively. The magnitude of the $\mathrm{D}^{*}$ oxygen tracer self-diffusion coefficient of $\mathrm{CZ}$, $\mathrm{CZP} 10$ and $\mathrm{CZP} 45$ was estimated at $\mathrm{T}=400^{\circ} \mathrm{C}$ from two independent measurements (IEDP and electronic conductivity relaxation). It strongly varies with the Pr content from $10^{-13} \mathrm{~cm}^{2} . \mathrm{s}$ ${ }^{1}$ (CZ) to $10^{-11} \mathrm{~cm}^{2} \cdot \mathrm{s}^{-1}$ (CZP10) and $10^{-8} \mathrm{~cm}^{2} \cdot \mathrm{s}^{-1}$ (CZP45). This evidences in particular a very good oxygen diffusion in CZP45 with a very high coefficient as compared to other good ionic conductors, especially at such low temperature. The reducibility and OSC properties of CZP series are comparable with the literature $^{3,4,5,22}$ with the best redox properties obtained for CZP45. The preparation of dense pellets sintering at $1400^{\circ} \mathrm{C}$ under air with the control of phase stability allows to measure accurately the transport properties and for the first time to estimate the high oxygen tracer self-diffusion coefficient in CZP45 sample.

\section{ASSOCIATED CONTENT}

\section{Supporting Information.}

The following file are available free of charge (Word document) via the internet at http : //pubs.acs.org.

Figures $\mathrm{S} 1$ shows the powder XRD patterns of $\mathrm{Ce}_{1-\mathrm{x}-\mathrm{y}} \mathrm{Zr}_{\mathrm{x}} \mathrm{Pr}_{\mathrm{y}} \mathrm{O}_{2}$ $z$ annealed at $1400^{\circ} \mathrm{C}$ under air. Figure S2 shows the thermal expansion behavior of CZP33 and CZP45 oxides. Figure S3 shows STEM light field image (left) analysis and EDX elementary analyses of CZP10 complex oxide (right, "three colors" images obtained by addition of the three elementary cartographies). Figure $S 4$ shows the temperature dependence of the magnetic susceptibility $\chi$ and the inverse $1 / \chi$ for the $\mathrm{Ce}_{0.45} \mathrm{Zr}_{0.1} \operatorname{Pr}_{0.45} \mathrm{O}_{2-\mathrm{z}}$ compound annealed at $700^{\circ} \mathrm{C}$ under air (experiments and fittings with the Curie-Weiss law). Figure S5 shows the oxygen vacancies ordering in $\mathrm{Pr}_{2} \mathrm{Zr}_{2} \mathrm{O}_{7}$ Pyrochloretype structure and the deduced oxygen vacancy environment ( $\square \mathrm{Zr}_{3} \mathrm{Pr}$ site) in the related fluorite-type network. Figure S6 shows TGA under air (speed rate : $5^{\circ} \mathrm{C} / \mathrm{min}$ ) performed on a 
$\mathrm{Ce}_{0.45} \mathrm{Zr}_{0.1} \operatorname{Pr}_{0.45} \mathrm{O}_{2-x}$ pellet (sintered under air at $1400^{\circ} \mathrm{C}$ ) and the estimation of $\mathrm{Pr}^{4+} / \mathrm{Pr}^{3+}$ molar concentration evolution versus temperature under air and $\mathrm{Ar} / \mathrm{H}_{2}$. Figure $\mathrm{S} 7$ shows the estimation (from TGA measurements under $\mathrm{Ar} / \mathrm{H}_{2}$ ) of $\mathrm{Pr}^{4+} / \mathrm{Pr}^{3+}$ molar concentration evolution versus temperature. Figure S8 shows the normalized oxygen concentration profiles recorded on dense pellets with CZ (left) and CZP10 (right) compositions, after a preliminary ${ }^{18} \mathrm{O}$ exchange performed at $\mathrm{T}=400^{\circ} \mathrm{C}$ during 1 h. Figure $\mathrm{S} 9$ shows the electronic conductivity relaxation profiles (experiments and fittings), recorded on CZP45 complex oxide and performed at $400^{\circ} \mathrm{C}$ and $700^{\circ} \mathrm{C}$. Table $\mathrm{S} 1$ shows the initial $\mathrm{Pr}^{4+}$ rates, $\Delta \mathrm{m} / \mathrm{m}$, deduced $\Delta \mathrm{O}$ exchanged oxygen and final $\mathrm{TR}^{4+} / \mathrm{TR}^{3+}$ molar contents after reduction (TGA- $\mathrm{Ar} / 5 \% \mathrm{H}_{2}$, or $\mathrm{H}_{2} / \mathrm{TPR}-\mathrm{Ar} / 1 \% \mathrm{H}_{2}$ ) of complex oxides $\mathrm{Ce}_{1-\mathrm{x}-\mathrm{y}} \mathrm{Zr}_{\mathrm{x}} \mathrm{Pr}_{\mathrm{y}} \mathrm{O}_{2-\mathrm{z}}$ (see Table 1 for oxides formulae) annealed at $\mathrm{T}=700{ }^{\circ} \mathrm{C}$ under air. Table $\mathrm{S} 2$ shows the probabilities for various local oxygen environments in CZP complex oxides deduced from multinomial law calculation (see table 1 for oxides formulae).

\section{AUTHOR INFORMATION}

\section{Corresponding Author}

* alain.demourgues@icmcb.cnrs.fr

\section{Author Contributions}

The manuscript was written through contributions of all authors. / All authors have given approval to the final version of the manuscript.

\section{Funding Sources}

The authors thank the PSA and SOLVAY companies for financial support.

\section{REFERENCES}

1. Trovarelli, A. Catalysis by ceria and related materials. (Imperial College Press, 2005).

2. Kaspar, J.; Fornasiero, P.; Hickey. N, Automotive catalytic converters : current status and some perspectives. .Catal. Today $\mathbf{2 0 0 3}$ 77, 419-449.

3. Bensaid, S.; Piumetti, M.; Novara, C.; Giorgis, F.; Chiodoni, A.; Russo, N.; Fino, D. Catalytic oxidation of $\mathrm{CO}$ and soot over Ce-ZrPr mixed oxides synthesized in a multi-inlet vortex reactor: effect of structural defects on the catalytic activity. Nano Res. Lett. 2016, 11(1), 494.

4. Andana, T.; Piumetti, M.; Bensaid, S.; Russo, N.; Fino, D.; Pirone, R. CO and soot oxidation over Ce-Zr-Pr oxide catalysts. Nano Res. Lett. 2016, 11(1), 278

5. Sinev, M. Y.; Graham, G. W.; Haack, L. P.; Shelef, M. Kinetic and structural studies of oxygen availability of the mixed oxides $\operatorname{Pr}_{1}$ ${ }_{x} \mathrm{M}_{\mathrm{x}} \mathrm{O}_{\mathrm{y}}(\mathrm{M}=\mathrm{Ce}, \mathrm{Zr})$. J. Mater. Res. 1996, 11, 1960-1971.

6. Rohart, E.; Verdier, S.; Demourgues, A.; Harlé, V.; Pacaud, B.; Baylet, A.; Takemori, H.; Suda, E.; Allain, M. New $\mathrm{CeO}_{2}-\mathrm{ZrO}_{2}$ mixed oxides with improved redox properties for advanced TWC catalysts. SAE Technical Paper. 2006.

7. Thomson, J. B.; Armstrong, A. R.; Bruce, P. G. A new class of pyrochlore solid solution formed by chemical intercalation of oxygen. J. Am. Chem. Soc. 1996, 118, 11129-11133.

8. Sasaki, T.; Ukyo, Y.; Kuroda, K.; Aral, S; Muto, S.; Saka, H. Crystal structure of $\mathrm{Ce}_{2} \mathrm{Zr}_{2} \mathrm{O}_{7}$ and $\beta-\mathrm{Ce}_{2} \mathrm{Zr}_{2} \mathrm{O}_{7.5}$. J. Ceram. Soc. Jpn. 2004, 112(8), 440-444.

9. Tolla, B.; Demourgues, A.; Isnard, O.; Menetrier, M.; Pouchard, M.; Rabardel, L.; Seguelong, T.; Structural investigation of oxygen insertion within the $\mathrm{Ce}_{2} \mathrm{Sn}_{2} \mathrm{O}_{7}-\mathrm{Ce}_{2} \mathrm{Sn}_{2} \mathrm{O}_{8}$ pyrochlore solid solution by means of in situ neutron diffraction experiments. J. Mater. Chem. 1999, 9, 3131-3136.

10. Muroi, T.; Echigoya, J.; Suto, H. Structure and phase diagram of $\mathrm{ZrO}_{2}-\mathrm{CeO}_{2}$ ceramics. Trans. Jpn. Inst. Met. 1988, 29, 634-641.

11. Von Dreele, R. B.; Eyring, L.; Bowman, A. L.; Yarnell, J. L. Refinement of the crystal structure of $\operatorname{Pr}_{7} \mathrm{O}_{12}$ by powder neutron diffraction. Acta Cryst. B 1975, 31, 971-974.

12. Eyring, L. The binary rare earth oxides. Handb. Phys. Chem. Rare Earths 1979, 3, 337-399.

13. Zhang, J.; Von Dreele, R. B.; Eyring, L. Structures in the oxygendeficient fluorite-related $\mathrm{RnO}_{2 \mathrm{n}-2}$ homologous series: $\operatorname{Pr}_{12} \mathrm{O}_{22}$. J. Solid. State Chem. 1996, 122, 53-58.

14. Abel, J.; Lamirand-Majimel, M.; Majimel, J.; Bellière-Baca, V.; Harlé, V.; André, A.; Prestipino, C.; Figueroa, S.; Durand, D.; Demourgues, A. et al. Oxygen non-stoichiometry phenomena in $\operatorname{Pr}_{1-\mathrm{x}} \mathrm{Zr}_{\mathrm{x}} \mathrm{O}_{2-\mathrm{y}}$ compounds $(0.02<\mathrm{x}<0.5)$. Dalton Trans 2014, 43, 15183-15191.

15. Wang, W.; Lin, P.; Fu, Y.; Cao, G. Redox properties and catalytic behavior of praseodymium-modified $(\mathrm{Ce}-\mathrm{Zr}) \mathrm{O}_{2}$ solid solutions in three-way catalysts. Catal. Lett. 2002, 82, 19-27.

16. Ran, R.; Weng, D.; Wu, X.; Fan, J.; Wang, L.; Wu, X. et al. Structure and oxygen storage capacity of Pr-doped $\mathrm{Ce}_{0.26} \mathrm{Zr}_{0.74} \mathrm{O}_{2}$ mixed oxides. J. Rare Earths 2011, 29, 1053-1059.

17. Fagg, D.; Kharton, V.; Shaula, A.; Marozau, I.; Frade, J. Mixed conductivity, thermal expansion, and oxygen permeability of $\mathrm{Ce}(\mathrm{Pr}, \mathrm{Zr})$ O. Sol. Stat. Ion. 2005, 176, 1723-1730.

18. Fagg, D. P.; Frade, J. R.; Kharton, V. V.; Marozau, I. P. The defect

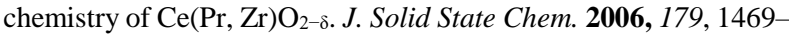
1477.

19. Kharton, V. V.; Viskup, A. P.; Figueiredo, F. M.; Naumovich, E. N.; Yaremchenko, A. A.; Marques, F. M. B. Electron-hole conduction in $\mathrm{Pr}$ doped $\mathrm{Ce}(\mathrm{Gd}) \mathrm{O}_{2-\delta}$ by faradaic efficiency and emf measurements. Electroch. Acta. 2001, 46, 2879-2889.

20. Kim, J. J.; Bishop, S. R.; Thompson, N. J.; Chen, D.; Tuller, H. L. Investigation of non-stoichiometry in oxide thin films by simultaneous in situ optical absorption and chemical capacitance measurements: Pr-doped Ceria, a case study. Chem. Mater. 2014, 26, 1374 1379.

21. Sravan, K.; K. B.; Deshpande, P. A. On identification of labile Oxygen in Ceria-Based Solid Solutions: Which Oxygen Leaves the Lattice? J. Phys. Chem. C 2015, 119, 8692-8702.

22. Rossignol, S.; Descorme, C.; Kappenstein, C.; Duprez, D. Synthesis, structure and catalytic properties of $\mathrm{Zr}-\mathrm{Ce}-\mathrm{Pr}-\mathrm{O}$ mixed oxides. J. Mater. Chem. 2001, 11, 2587-2592.

23. De Souza, R. A.; Zehnpfenning, J.; Martin, M.; Maier, J. Determining oxygen isotope profiles in oxides with time-of flight SIMS. Solid State Ionics. 2005, 176, 1465-1471.

24. Bassat, J.-M.; Petitjean, M.; Fouletier, J.; Lalanne, C.; Caboche, G.; Mauvy, F.; Grenier, J. C. Oxygen isotopic exchange: A useful tool for characterizing oxygen conducting oxides. Appl. Catal. Gen. 2005, 289, 84-89.

25. Crank, J. The mathematics of diffusion. (Clarendon Press, 1976).

26. Hernández-Velasco, J. Unusual magnetic behaviour in Sr2PrO4. J. Magn. Magn. Mater. 2007, 310, 1669-1671.

27. Hatnean, M. C.; Sibille, R.; Lees, M. R.; Kenzelmann, M.; Ban, V.; Pomjakushin, V.; Balakrishnan, G. Single crystal growth, structure and magnetic properties of $\mathrm{Pr}_{2} \mathrm{Hf}_{2} \mathrm{O}_{7}$ pyrochlore. J. Phys. Condens. Matter 2017, 29, 75902.

28. Matsuhira, K.; Sekine, C.; Paulsen, C.; Wakeshima, M.; Hinatsu, Y.; Kitazawa, T.; Kiuchi, Y.; Hiroi, Z.; Takagi, S. Spin freezing in the pyrochlore antiferromagnet $\operatorname{Pr}_{2} \mathrm{Zr}_{2} \mathrm{O}_{7}$. J. Phys. Conf. Ser. 2009, 145,12031

29. Porter, S. H.; Huang, Z.; Cheng, Z.; Avdeev, M.; Chen, Z.; Dou, S.; Woodward, P. M. Structural and magnetic properties of $\mathrm{RTiNO} 2(\mathrm{R}=\mathrm{Ce}, \mathrm{Pr}, \mathrm{Nd})$ perovskite nitride oxides. J. Solid State Chem. 2015, 226, 279-285. 
30. Malchus, M.; Jansen, M. Electrocrystallization of $\mathrm{PrO}_{2}$ and $\mathrm{TbO}_{2-x}$ from alkali hydroxide melts and characterization of the fluorite-related $\mathrm{TbO}_{2-\mathrm{x}}$. Solid State Sci. 1998, 2, 65-70.

31. Aruna, S. T.; Kini, N. S.; Shetty, S.; Rajam, K. S. Synthesis of nanocrystalline $\mathrm{CeAlO}_{3}$ by solution-combustion route. Mater. Chem. Phys. 2010, 119, 485-489.

32. Hatnean, M. C.; Decorse, C.; Lees, M. R.; Petrenko, O. A.; Keeble, D. S.; Balakrishnan, G. Structural and magnetic properties of single-crystals of the geometrically frustrated zirconium pyrochlore, $\mathrm{Pr}_{2} \mathrm{Zr}_{2} \mathrm{O}_{7}$. Mater. Res. Express 2014, 1, 26109.

33. Alessandri, I.; Banares, M. A.; Depero, L. E.; Ferroni, M.; Fornasiero, P.; Gennari, F. C.; Hickey, N.; Martinez-Huerta, M. V.; Montini, T. Structural investigation of $\mathrm{Ce}_{2} \mathrm{Zr}_{2} \mathrm{O}_{8}$ after redox treatments which lead to low temperature reduction. Top. Catal. 2006, 41, 3542.

34. Lal, H. B.; Gaur, K. Electrical conduction in non-metallic rare-earth solids. J. Mater. Sci. 1988, 23, 919-923.

35. B.C.H. Steele and J.M. Bae, Properties of $\mathrm{La}_{0.6} \mathrm{Sr}_{0.4} \mathrm{Co}_{0.2} \mathrm{Fe}_{0.8} \mathrm{O}_{3-x}$ (LSCF) double layer cathodes on gadolinium-doped cerium oxide (CGO) electrolytes: II. Role of oxygen exchange and diffusion, Solid State Ionics 1998, 106, 255-261.

36. M. Burriel, H. Tellez, R.J. Chater, R. Castaing, P. Veber, M. Zaghrioui, T. Ishihara, J.A. Kilner and J.M. Bassat Influence of crystal orientation and annealing on the oxygen diffusion and surface exchange of $\mathrm{La}_{2} \mathrm{NiO}_{4+\delta}$, J. Phys. Chem. C. 2016, 120, 1792717938. 


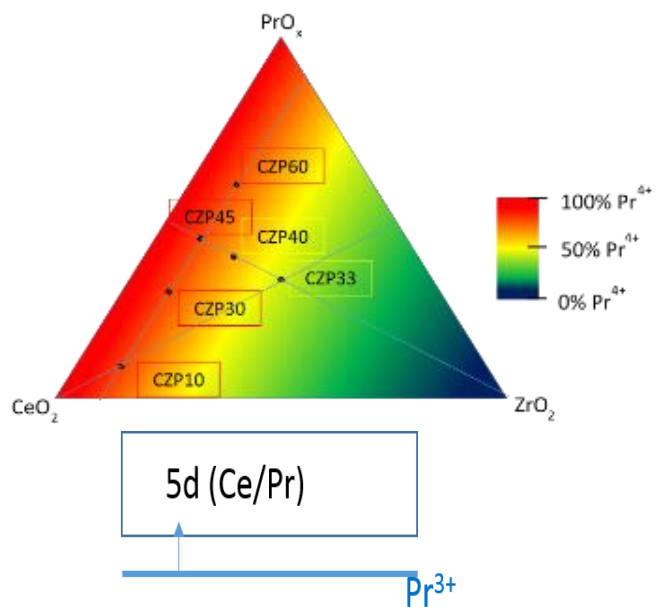

n-type SC behavior $(0.38 \mathrm{eV})$ at low $\mathrm{T}$

p-type SC behavior $(0.17 \mathrm{eV})$ at $\mathrm{T}>520^{\circ} \mathrm{C}$

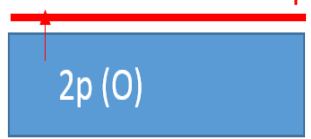

